\title{
Negative Hydrogen Ion Sources for Accelerators
}

\author{
Douglas P. Moehs, Jens Peters, and Joseph Sherman
}

Invited Paper

\begin{abstract}
A variety of $\mathrm{H}^{-}$ion sources are in use at accelerator laboratories around the world. A list of these ion sources includes surface plasma sources with magnetron, Penning and surface converter geometries as well as magnetic-multipole volume sources with and without cesium. Just as varied is the means of igniting and maintaining magnetically confined plasmas. Hot and cold cathodes, radio frequency, and microwave power are all in use, as well as electron tandem source ignition. The extraction systems of accelerator $\mathrm{H}^{-}$ion sources are highly specialized utilizing magnetic and electric fields in their low energy beam transport systems to produce direct current, as well as pulsed and/or chopped beams with a variety of time structures. Within this paper, specific ion sources utilized at accelerator laboratories shall be reviewed along with the physics of surface and volume $\mathrm{H}^{-}$production in regard to source emittance. Current research trends including aperture modeling, thermal modeling, surface conditioning, and laser diagnostics will also be discussed.
\end{abstract}

Index Terms-Accelerator, beam, beam transport, emittance, injector, ion, ion source, negative hydrogen, phase space, plasma, simulation.

\section{INTRODUCTION}

$\mathbf{O}$ VER THE years, many excellent review articles and texts have been written to discuss $\mathrm{H}^{-}$ion sources, beams, and their applications. An early review [1] summarizes both experimental and theoretical work on $\mathrm{H}^{-}$sources up to 1973, and is suggestive of the major advances that will occur in $\mathrm{H}^{-}$sources in the following decades. Seven Brookhaven National Laboratory Symposia from 1977 to 1995, under the title "Production and Neutralization of Negative Ions and Beams" [2]-[8], document the considerable advances made in $\mathrm{H}^{-}$sources and beams over these two decades. Essentially, all of the $\mathrm{H}^{-}$sources operating on accelerators today have their physical bases described in this conference series. References [9]-[12] are relevant $\mathrm{H}^{-}$source reviews for accelerator applications, while [13]-[16] focus on high power, high intensity requirements for accelerators such as the spallation neutron source (SNS), the European spallation source (ESS), the CERN

Manuscript received April 26, 2005; revised June 27, 2005. This work was supported in part by the University Research Associates Inc., under Contract DE-AC02-76CH03000, in part by the European Economic Community (EEC) under Contract HPRI-CT-2001-50021, in part by the Los Almos National Laboratory LANSCE Division, and in part by the U.S. Department of Energy.

D. P. Moehs is with the Fermi National Acclerator Laboratory, Batavia, IL 60510 USA (e-mail: moehs@fnal.gov).

J. Peters is with the Deutsches Elektronen-Synchrotron (DESY), 22607 Hamburg, Germany (e-mail: jens.peters@desy.de).

J. Sherman, retired, was with the Los Alamos National Laboratory, Los Alamos, NM 87545 USA (e-mail: shermanjoe@ @aol.com).

Digital Object Identifier 10.1109/TPS.2005.860067 superconducting proton linac (SPL), the KEK/Japan Atomic Energy Research Institute Joint Project (J-PARC) and the Los Alamos Neutron Science Center (LANSCE), Los Alamos National Laboratory (LANL), Los Alamos, NM, upgrade projects. The principal efforts in $\mathrm{H}^{-}$source technology today are directed toward fusion energy applications (described elsewhere in this volume), and comparatively low-emittance $\mathrm{H}^{-}$sources with long duty factor (up to continuous wave (CW) mode) for high-energy accelerator applications. It is the goal of this paper to summarize performance characteristics of the $\mathrm{H}^{-}$sources used in accelerator applications.

The following two major sections summarize 1) $\mathrm{H}^{-}$source fundamentals and 2) a summary of the $\mathrm{H}^{-}$source types and their characteristics that are presently in operation at major accelerator facilities. For topic 1), phase-space area (beam emittance), some details of $\mathrm{H}^{-}$plasma temperature, plasma fluctuations which lead to $\mathrm{H}^{-}$beam current fluctuations, and ion optics at extraction will be discussed. For topic 2), pure $\mathrm{H}_{2}$ multicusp volume, cesiated multicusp, and cesiated surface plasma $\mathrm{H}^{-}$source performances are summarized (see Sections III and IV). The cesiated surface plasma sources (SPS) include Penning, magnetron, and surface converter type geometries. $\mathrm{H}^{-}$ beam currents $\left(I_{\mathrm{H}^{-}}\right)$and their beam emittances will be summarized. The discharge power $\left(P_{d}\right)$ required to maintain the source plasma and the power efficiency of the $\mathrm{H}^{-}$beam, $\varepsilon=$ $\left(I_{\mathrm{H}}-(m A) / P_{d}(k W)\right)$, are also summarized wherever possible. Electrons are co-extracted with the $\mathrm{H}^{-}$ions, and as the duty factor (df) increases, the extracted electron current $\left(I_{e}\right)$ to $\mathrm{H}^{-}$ current ratio $\Gamma=\left(I_{e} / I_{\mathrm{H}}^{-}\right)$gains increasing practical importance. Here beam $\mathrm{df}$ is given by the product of beam pulsewidth times the repetition rate. Note that the source df might be considerably larger than the beam df, as beam may be extracted over a limited part of the source discharge time. The achieved $\Gamma$ and beam $\mathrm{df}$ for the various sources are summarized. The source lifetime at the design beam voltage $\left(V_{b}\right), \mathrm{H}^{-}$current and $\mathrm{df}$ is given. Although these latter quantities are not perhaps as fundamental to accelerator operations as beam current and emittance, they must nevertheless be taken into account in any practical $\mathrm{H}^{-}$ source accelerator application.

\section{II. $\mathrm{H}^{-}$SOURCE FundAMENTALS}

\section{A. Beam Emittance}

A general review of ion source and injector emittance is given in [17]. An ion source emittance should be preserved in the injector, the injector being that accelerator element that transmits 
the $\mathrm{H}^{-}$beam extracted from the source plasma to the next accelerator section. Beyond electron filtering and ion extraction systems, injector types will not be discussed in detail in this review. Laboratory beam emittance $\left(\varepsilon_{L}\right)$ is defined as

$$
\varepsilon_{L}=\frac{A\left(x, x^{\prime}\right)}{\pi}=\left(\frac{1}{\pi}\right) \iint d x d x^{\prime}
$$

where $A\left(x, x^{\prime}\right)$ is the phase space area occupied by the beam. The $x$ and $x^{\prime}$ are spatial and angle coordinates transverse to the beam direction. The calculated area value is divided by $\pi$ and typically the unit $(\pi \mathrm{cm}-\mathrm{mrad})$ or $(\pi \mathrm{mm}-\mathrm{mrad})$ is then attached to $\varepsilon_{L}$. In order to make comparisons among $\mathrm{H}^{-}$sources that have beams at different energies, $T_{b}=e V_{b}$, a normalized emittance is defined

$$
\varepsilon_{n}=\beta \varepsilon_{L}
$$

where $\beta$ is the relativistic velocity factor corresponding to $T_{b}$. Equation (2) is valid for low energies $\left(T_{b} \ll m_{\mathrm{H}-} c^{2}\right.$, where $m_{\mathrm{H}^{-}} c^{2}$ is the $\mathrm{H}^{-}$rest mass in electronvolts and the relativistic mass factor $\gamma=1$ ). Equation (2) is appropriate at typical $\mathrm{H}^{-}$ source energies. Implied in (1) is that emittance data is obtained from a slit and collector or a two-slit system, where the orthogonal transverse coordinates $\left(y, y^{\prime}\right)$ are integrated by the measurement technique. Discussion of $\left(r, r^{\prime}\right)$ measurements is found in the literature [18], and is discussed below in regard to $\mathrm{H}^{-}$extraction physics with two-dimensional (2-D) axisymmetric design codes.

Most computerized emittance diagnostic systems analyze the beam intensity distribution $I\left(x, x^{\prime}\right)$ to give the beam emittance as a function of the beam fraction $(F)$. This is a valuable exercise for at least two reasons. First, beam theory often describes the phase-space area in terms of root mean square (rms) emittance $\left(\varepsilon_{\mathrm{rms}}\right)$ [19], [20] which is based on the second moments of $x$ and $x^{\prime}$. Beam emittance fraction analysis under reasonable assumptions gives a relationship between $\varepsilon_{\mathrm{rms}}$ and laboratory emittance measured at the fraction $F, \varepsilon_{L}(F)$. For a Gaussian beam [21], [22], the relation among $F, \varepsilon_{\mathrm{rms}}$, and $\varepsilon_{L}(F)$ is given by

$$
F=1-e^{\left(-\varepsilon_{L}(F) / 2 \varepsilon_{\mathrm{rms}}\right)} .
$$

A second reason for obtaining $\varepsilon_{L}(F)$ is that knowledge of emittance at $95 \%$ beam fraction is often desired to evaluate beam losses in high-energy accelerator components [23]. By solving (3) for $\varepsilon_{L}(F)=\varepsilon_{\mathrm{rms}}$, one finds $F=0.40$, that is, $\varepsilon_{\mathrm{rms}}$ corresponds to about $40 \%$ beam fraction. Similarly, by taking $F=0.95$, one finds $\varepsilon_{L}(0.95)=6 \varepsilon_{\text {rms }}$. These relationships can be used to make approximate comparisons among measured $\mathrm{H}^{-}$ source emittances, where quoted emittance results are not all reported at the same $F$.

A sophisticated treatment of background in measured transverse phase space distributions has been developed, and applied to several $\mathrm{H}^{-}$sources [24], [25]. Except for the magnetron source, which is subject to emittance growth associated with extracting $\mathrm{H}^{-}$ions directly from the cathode, the surface converter, Penning SPS, and cesiated multicusp $\mathrm{H}^{-}$sources were found to have nearly the same emittance. Within [22], [24] several plots of $\varepsilon_{L}(F)$ versus $\ln (1-F)^{-1}$ are made, and an approximate linear relationship is found. The slope of this line is the $2 \varepsilon_{\text {rms }}$ value. Constructing this plot is a valuable exercise to see if the beam emittance has a Gaussian distribution, and at what beam fraction the distribution deviates from Gaussian. A knee in this plot may signify the onset of aberrations in the extraction or beam transport systems that may ultimately be solved by more appropriate design considerations. More recently this emittance analysis technique has been applied to false particle ("ghost") signals [26] in the two-slit electric sweep scanner [27].

\section{B. $\mathrm{H}^{-}$Temperture in Plamsa}

A prediction for the rms normalized emittance $\varepsilon_{n, \mathrm{rms}}$ [21], [28] at the $\mathrm{H}^{-}$source emission aperture with radius $R$ is given by

$$
\varepsilon_{n, \mathrm{rms}}=\left(\frac{R}{2}\right) \sqrt{\frac{k T_{\mathrm{H}^{-}}}{m_{\mathrm{H}^{-}} c^{2}}}
$$

where $k T_{\mathrm{H}^{-}}$is the $\mathrm{H}^{-}$ion plasma temperature. The units of $\varepsilon_{n, \mathrm{rms}}$ are the spatial unit of $R$ (usually millimeters or centimeters) and radians. At least two measurement types for $k T_{\mathrm{H}^{-}}$have been made on accelerator sources: first, volume $\mathrm{H}^{-}$production [29]-[31] using a two-laser photodetachment technique; and second, the SPS Penning $\mathrm{H}^{-}$source [32], [33] equipped with a long emission slit and measurement of the extracted $\mathrm{H}^{-}$angle distribution in the orthogonal plane with an electric sweep scanner [27]. In the case of the photodetachment technique used in volume production, two distributions corresponding to cold and hot temperatures are found. Depending on source operation, $k T_{\mathrm{H}^{-}}($cold $)=0.027-0.22 \mathrm{eV}$ and $k T_{\mathrm{H}^{-}}$(hot) $=0.35-1.43 \mathrm{eV}$ were found. In the case of the SPS Penning source, $k T_{\mathrm{H}^{-}}=0.1-0.2 \mathrm{eV}$ was found for low discharge current $(2 \mathrm{~A} \mathrm{dc})$ operation. The Penning source $\mathrm{H}^{-}$temperature increased to $0.8-1.0 \mathrm{eV}$ for the high-current (350 A) pulsed discharge case. Emittance calculations based on $k T_{\mathrm{H}^{-}}$measurements and (4) are typically lower than $\mathrm{H}^{-}$ source measurements. Additional contributions to source emittance are thus expected and other source emittance growth mechanisms are discussed in Section II-C.

\section{Plasma Fluctuations, Beam Noise, and Multiple Beams}

The influence of plasma fluctuations in the generation of $\mathrm{H}^{-}$beams with time varying current (beam noise) and the possibility of "two beams" being born at the plasma meniscus can rapidly degenerate the intrinsic emittance of an ion source and cause subsequent problems in accelerator transmission. The noise characteristics of the SPS Penning [34], [35] and magnetron [36] discharges have been investigated. A guideline for dynamic decomposition of beam space-charge neutralization [37] is given by

$$
\alpha f \gg \frac{\left(v_{-} n_{0} \sigma_{i}\right)}{2} .
$$

The beam noise amplitude and frequency are $\alpha$ and $f$. The $\mathrm{H}^{-}$beam velocity is $v_{-}, n_{0}$ is the neutral background gas density, and $\sigma_{i}$ is the ionization cross section of the background 
gas by the $\mathrm{H}^{-}$beam. When the inequality is satisfied, a time dependent space charge force exists leading to a time averaged emittance growth. Substituting typical ion source numbers, the right side of (5) gives $20 \mathrm{kHz}$, thus significant effects from beam space charge decomposition may be expected in the hundreds of kilohertz to megahertz beam noise frequency range. Typically, these considerations apply to injectors that use magnetic lenses in beam transport.

Various analytic techniques can be applied to evaluate emittance growth from beam noise. One analytic approach follows a current fluctuation with the Kapchinskii-Vladimirskii equations through a beam transport channel [38]. A second method is to define a mismatch factor $\eta$ [38], [39], which is a combination of the matched and mismatched Courant-Snyder parameters. The time-averaged emittance growth $\left(\varepsilon_{T A}\right)$ is then given by $\varepsilon_{T A}=\eta \varepsilon_{\text {int }}$, where $\varepsilon_{\text {int }}$ is the beam emittance with $\alpha=0$.

In the SPS magnetron geometry, extracted $\mathrm{H}^{-}$ions have been determined to have two energies: those characterized by $\mathrm{H}^{-}$ born on the cathode, and those that originate from the ion source volume and/or anode potential [40], [41] (see Section III-C). The LANSCE H $\mathrm{H}^{-}$converter source [42], [43] has a geometry similar to the SPS magnetron in that the converter $\left(\mathrm{H}^{-}\right.$ origin) is in line-of-sight to the source emission and extraction apertures. It has recently been proposed that a large emittance growth observed in a recent LANSCE development program [44] can be attributed to two simultaneously extracted beams. Those two beams are characterized by two $\mathrm{H}^{-}$plasma species with plasma energy (1-10 eV) and converter energy (250-300 eV). Measured test-stand phase-space distributions are highly suggestive of two beams at $80 \mathrm{keV}$ that can be characterized by two independent Courant-Snyder parameters. Beam extraction simulations, as well as the mismatch calculations described above, reproduce the measured emittance growths. If this proposal is confirmed, emittance growth attributable to mismatched Courant-Snyder parameters may be extended to time independent as well as time dependent phenomena.

\section{Beam Optics at $\mathrm{H}^{-}$Extraction}

Much effort in $\mathrm{H}^{-}$source development is expended on improving the $e / \mathrm{H}^{-}$ratio in extracted $\mathrm{H}^{-}$beams, and to achieve the lowest possible emittance growth in the extraction process. Maintaining a low $e / \mathrm{H}^{-}$ratio is especially important for the longer df sources; the experimental results from this effort are reported in Section III. Magnetic and electric filtering techniques are used to separate electrons and $\mathrm{H}^{-}$ions. An increasing theoretical effort to minimize the $e / \mathrm{H}^{-}$ratio in the plasma region near extraction using particle-in-cell codes (PIC) is underway [45], [46].

Prior to extraction, the plasma density affects the $e / \mathrm{H}^{-}$ ratio. For example, $\mathrm{H}^{-}$may be destroyed by electron collisions through the collisional detachment process (6). An $\mathrm{H}^{-}$loss rate

$$
\begin{aligned}
e+\mathrm{H}^{-} & \rightarrow H+2 e \\
N(t) & =N(t=0) e^{-n\langle\sigma v\rangle t}
\end{aligned}
$$

equation for this process is given in (7) where $N(t)$ is the $\mathrm{H}^{-}$ density at time $t$, and $n$ is the electron density. Using the reaction rate $\langle\sigma v\rangle=7 \times 10^{-7}\left(\mathrm{~cm}^{3} / \mathrm{s}\right)$ from [1], and assuming an $\mathrm{H}^{-}$ velocity $v=10^{6} \mathrm{~cm} / \mathrm{s}$ and $n=10^{12}(\mathrm{~cm})^{-3}$, one finds half the $\mathrm{H}^{-}$population is destroyed in $1 \mathrm{~cm}$. Detailed simulation of $\mathrm{H}^{-}$destruction processes have been modeled in the threedimensional (3-D) NIETZSCHE Monte Carlo code [47].

In order to minimize emittance growth in the $\mathrm{H}^{-}$ion extraction process, codes based on the successive over relaxation technique originally developed for positive ion extraction electrode design [48]-[50] are being used and developed for the $\mathrm{H}^{-}$extraction problem. These codes take into account the high space-charge forces encountered in the extraction process, and include algorithms to make a self-consistent prediction for the plasma sheath position and shape. The PBGUNS code [50], which does include a positive and negative ion Maxwellian distribution (for emulating the $\mathrm{H}^{-}$plasma temperature), has proven useful in describing some $\mathrm{H}^{-}$source problems [44], [51]. The IGUNS extraction code used in [48] now includes more comprehensive modeling [52], [53], of the $\mathrm{H}^{-}$and electrons for $\mathrm{H}^{-}$ source design, and is incorporated in the nIGUN code [54].

The 2-D axisymmetric codes discussed above use cylindrical coordinates for trajectory description. Cylindrical coordinates imply coupling of the radial and azimuthal motions, and it is useful to employ a meridional plane if one is interested only in radial motion. Thus, these codes may use post-processing routines on the $\left(r_{n}, r_{n}^{\prime}\right)$ coordinates to calculate rms beam quantities at selected axial positions in the simulation. As noted above, most beam emittance measurements are made in $\left(x, x^{\prime}\right)$ coordinates. Thus, to obtain a comparison between a $\left(r, r^{\prime}\right)$ prediction and $\left(x, x^{\prime}\right)$ measurement, a coordinate transformation must be made [55], [56]. A physical interpretation of the relationship between $\varepsilon_{L, \mathrm{rms}}$ and $\varepsilon\left(r, r^{\prime}\right)_{\mathrm{rms}}$ gives $\varepsilon_{L, \mathrm{rms}}=\varepsilon\left(r, r^{\prime}\right) / \sqrt{2}$ when $\theta$ motion is taken into account [57].

\section{ACCElERATOR $\mathrm{H}^{-}$SOURCE REVIEW}

\section{A. Uncesiated Multicusp $\mathrm{H}^{-}$Volume Sources}

1) Desy Volume Source: The DESY-HERA RF volume source [58] uses an external RF antenna to couple power into the source plasma. The coil, operated at $2 \mathrm{Mhz}$, is located behind a $5 \mathrm{~mm}$ thick $\mathrm{Al}_{2} \mathrm{O}_{3}$ ceramic cylinder [59], see Fig. 1. $\mathrm{Al}_{2} \mathrm{O}_{3}$ has a very low sputter rate and ion bombardment is reduced due to the low RF plasma modulation associated with the external antenna system. For ignition, a special source was developed [60] which works with the high pressure of the hydrogen inlet. A lifetime of much more than a year with an $\mathrm{H}^{-}$current of $40 \mathrm{~mA}$ and a duty factor of $0.12 \%$ has been demonstrated. The $90 \% \mathrm{rms}$ normalized emittance for $40 \mathrm{~mA}$ is $0.25 \pi \mathrm{mm}-\mathrm{mrad}$ in both transverse planes. The collar is biased and made adjustable in position and angle. Extracted electrons are dumped with a permanent magnet into a shielded box. A second magnet corrects the $\mathrm{H}^{-}$beam, which then travels parallel to the source center line [61].

The use of Cs was ruled out in order to achieve high stability and reduce maintenance. This source produces $\mathrm{H}^{-}$purely through the volume effect. Energetic electrons generate vibrationally excited hydrogen molecules $\left(\mathrm{H}_{2}+\mathrm{e}^{-} \rightarrow \mathrm{H}_{2}^{*}+\mathrm{e}^{-}\right)$ in the discharge chamber. A dipole magnet pair allows heavy elements and low energy electrons (typically $<2 \mathrm{eV}$ ) to pass into the extraction region. These low energy electrons may 


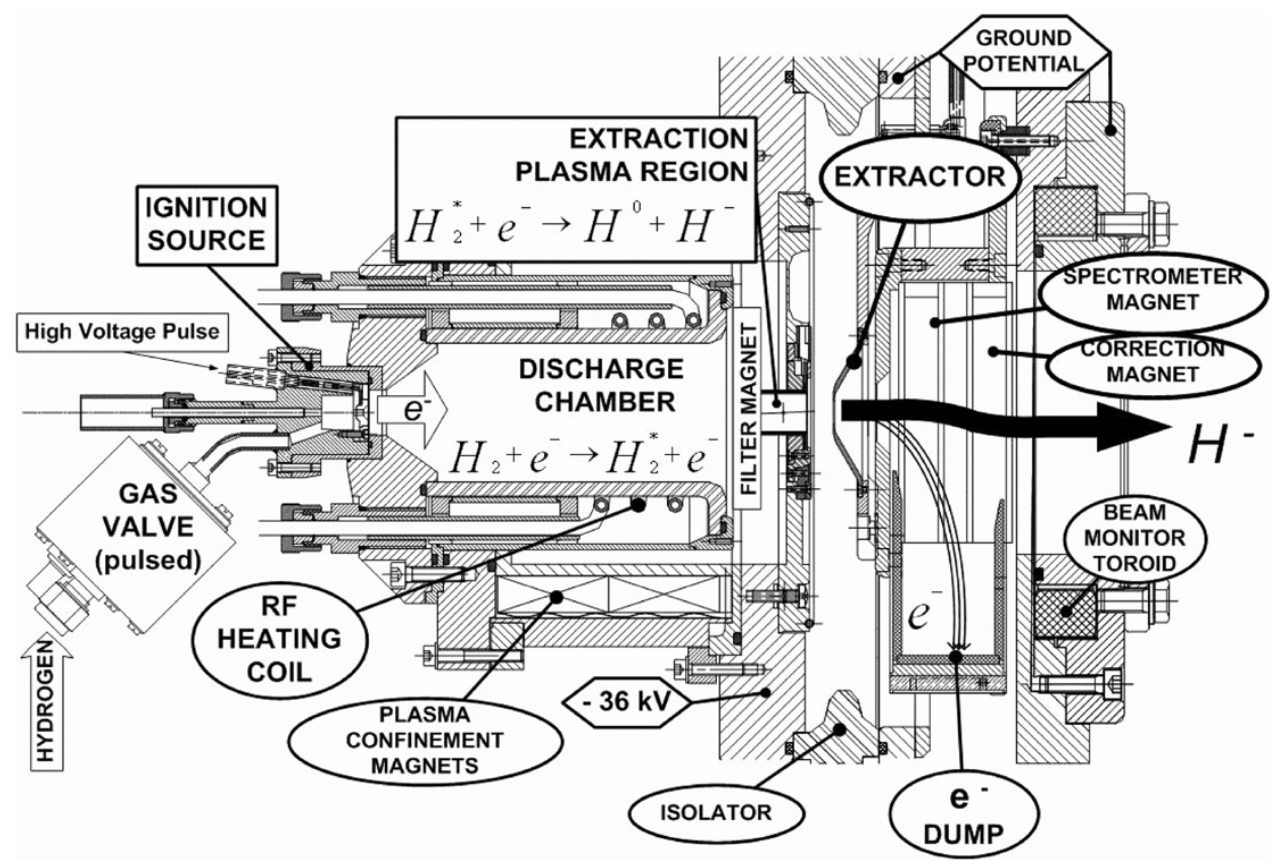

Fig. 1. DESY-HERA RF volume source with external antenna and ignition source.

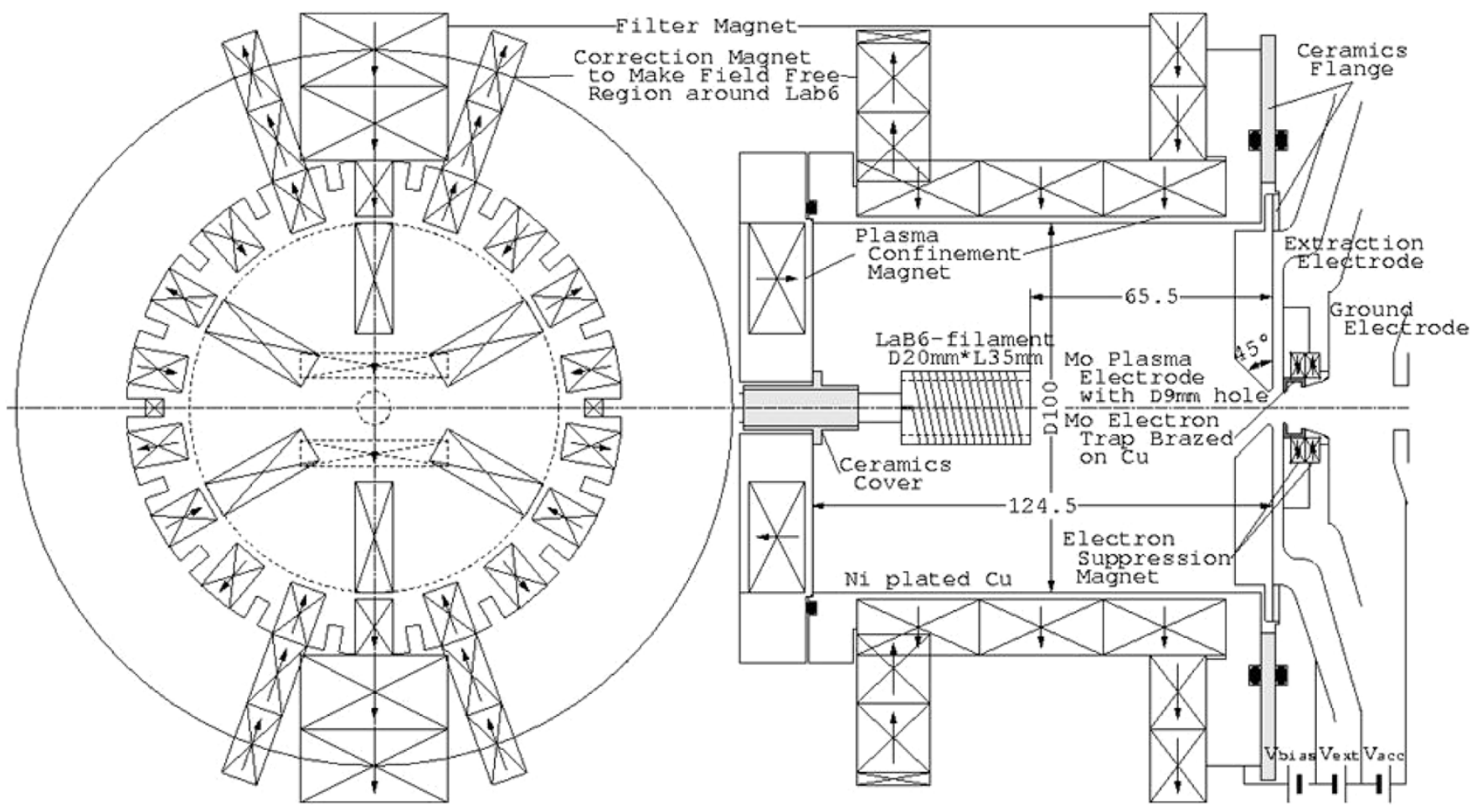

Fig. 2. Drawing of J-PARC ion source KEK prototype with $\mathrm{LaB}_{6}$ filament. (Reused with permission from A. Ueno, Rev. Sci. Instrum., 75, 1714 (2004). Copyright 2004, Amer. Inst. Phys.)

then attach to the vibrationally excited molecules to form $\mathrm{H}^{-}\left(\mathrm{H}_{2}^{*}+\mathrm{e}^{-} \rightarrow \mathrm{H}^{0}+\mathrm{H}^{-}\right)$[31], [62].

2) J-PARC $\mathrm{LaB}_{6}$ Source: A KEK prototype source with a $\mathrm{LaB}_{6}$ filament (see Fig. 2) is presently in use at the Japan Proton Accelerator Research Complex (J-PARC) LINAC project where $30 \mathrm{~mA}$ of $\mathrm{H}^{-}$was accelerated in the LINAC to $20 \mathrm{MeV}$ [63]. The cesium free source itself has demonstrated an $\mathrm{H}^{-}$current of $38 \mathrm{~mA}$ with a duty factor of $0.9 \%(360 \mu \mathrm{s} \times 25 \mathrm{~Hz})$ at 50
$\mathrm{keV}$. Development is underway [64] to use W-filaments, $\mathrm{a} \mathrm{LaB}_{6}$ cathode, or a RF coil in the source discharge chamber. As part of this work, the original cylindrical source chamber was reduced $50 \%$ to $10 \mathrm{~cm}$ in diameter and $12.5 \mathrm{~cm}$ in length.

The plasma is confined with the usual multicusp magnet arrangement (18 bar rows). The filter magnets are outside of the plasma saddled on the top and bottom cusp magnets. The insulated plasma electrode plate has a 9-mm-diameter beam hole, 


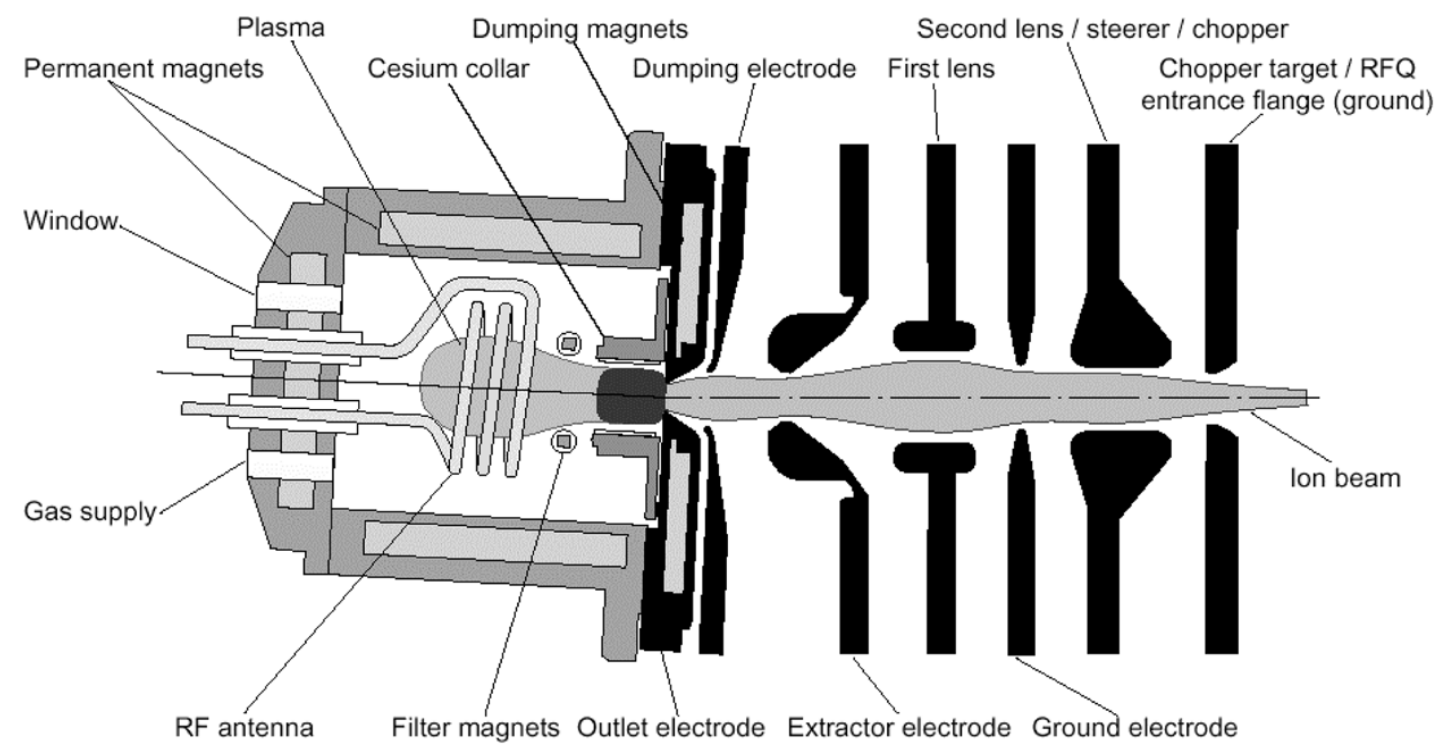

Fig. 3. Drawing of the SNS cesiated multicusp $\mathrm{H}^{-}$source and low-energy beam transport system [67]. (Reused with permission from R. Keller, Rev. Sci. Instrum., 73, 914, (2002). Copyright 2002, Amer. Inst. Phys.)

thickness of $10 \mathrm{~mm}$ and internal angle of $45^{\circ}$. This configuration gave the best results in a series of tests with plates of different angles and thicknesses. The plate was run with a bias, negative to the source body, of $12.6 \mathrm{~V}$ that attracts positive ions.

The extracted electrons are accelerated to $8 \mathrm{keV}$ and then dumped into a gap with a set of dipole permanent magnets. The $\mathrm{H}^{-}$beam, which also gets deflected, is subsequently corrected with a second magnet pair poled in the opposite direction.

\section{B. Cesiated Multicusp $\mathrm{H}^{-}$Sources}

1) SNS/LBNL Radio-Frequency Multicusp $\mathrm{H}^{-}$Source: The SNS multicusp ion source is now being used to commission the drift tube linac at the SNS [65]. Ultimately, this facility will produce a 1.4-MW beam of protons at $1 \mathrm{GeV}$. In order to meet this requirement, the ion source needs to produce $40 \mathrm{~mA}$ of $\mathrm{H}^{-}$ at a $6 \% \mathrm{df}, 1$-ms-long pulses at $60 \mathrm{~Hz}$ [66], one of the most demanding $\mathrm{H}^{-}$source requirements to date [14].

During ion extraction, the plasma of the SNS multicusp source is excited using $20-50 \mathrm{~kW}$ of $2 \mathrm{MHz}$ RF. To speed the high powered ignition, the plasma is sustained continually with $200 \mathrm{~W}$ of $13.56 \mathrm{MHz} \mathrm{RF}$ [67]. The RF power is coupled into the plasma using an internal water-cooled copper-antenna that is coated with porcelain. Pin-hole cracks in the porcelain quickly lead to antennae failures. This problem is minimized by using multiple layers of $\mathrm{TiO}_{2}$ free porcelain up to $1 \mathrm{~mm}$ thick. Removing the $\mathrm{TiO}_{2}$, a standard color additive, reduces the dielectric strength, and helps minimize the electric field in the plasma sheath [68].

In order to obtain high $\mathrm{H}^{-}$currents, both volume and anode surface production processes are utilized. The surface processes are enhanced by introducing $\mathrm{Cs}$ into the source using $\mathrm{Cs}_{2} \mathrm{CrO}_{4}$ and a getter material made of $\mathrm{Al}$ and $\mathrm{Zr}$ that reduces the chromate to elemental cesium at elevated temperatures. Dispensers of this mixture are mounted in a collar surrounding the extraction aperture, which can be independently heated to $550{ }^{\circ} \mathrm{C}$ thereby releasing Cs, see Fig. 3. Cesiation is needed every few

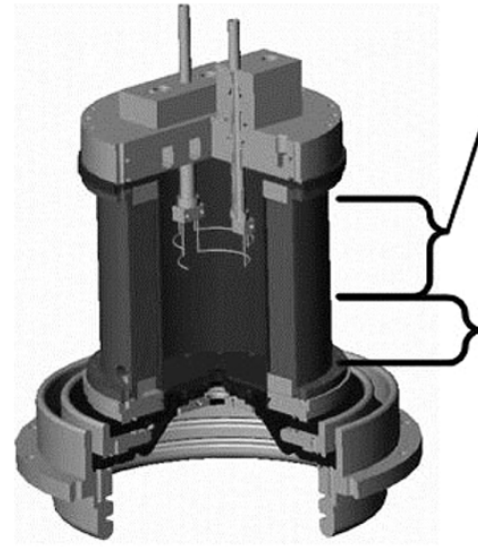

(a)

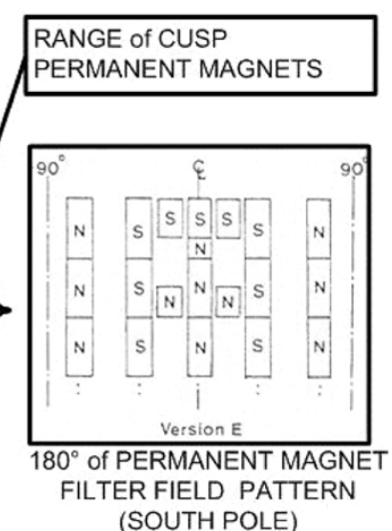

(b)
Fig. 4. (a) TRIUMF source (courtesy of T. Zhang, China Institute of Atomic Energy) with Ta ring filament and (b), an example of the filter magnet pattern (courtesy of T. Kuo, TRIUMF).

days to maintain the required currents. Because useful $\mathrm{H}^{-}$production only takes place in the extraction region, a direct Cs transfer technique is being developed to insure optimum Cs coverage of surfaces near the extraction aperture which are constantly being "cleaned" by particle bombardment of the plasma [69], [70].

Running Cs free, the SNS volume source produces 10-15 $\mathrm{mA}$ of $\mathrm{H}^{-}$. Upon cesiation, the output current presently reaches $30-40 \mathrm{~mA}$ implying surface production is directly responsible for $25-30 \mathrm{~mA}$ (aprox. 70\%) of the beam current [70]. A horizontal normalized emittance of $0.115 \pi \mathrm{mm}-\mathrm{mrad}$ (rms) has been measured at $28 \mathrm{~mA} \mathrm{[26],} \mathrm{[71].} \mathrm{At} 33 \mathrm{~mA}$, horizontal and vertical normalized (rms) emittances of 0.22 and 0.18 $\pi$ mm-mrad were reported in [25]. Efforts to increase the $\mathrm{H}^{-}$ surface production were recently carried out by integrating the outlet aperture and Cs collar. Upon cesiation, a beam current of $60 \mathrm{~mA}$ was achieved. However, shoulders to the main beam spot also appeared (cf. [70, Fig. 11]) resulting in a normalized 


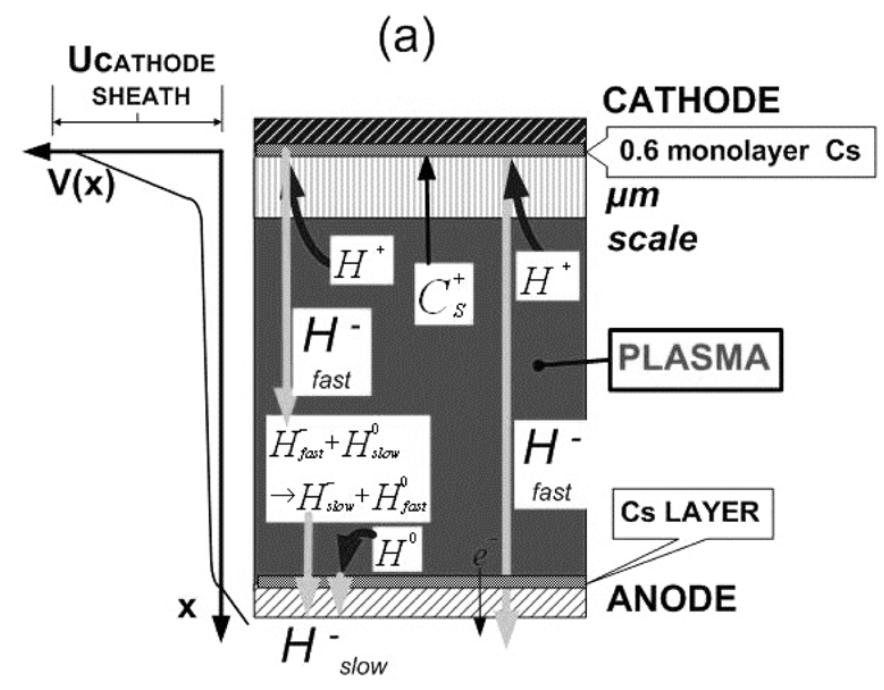

(b)

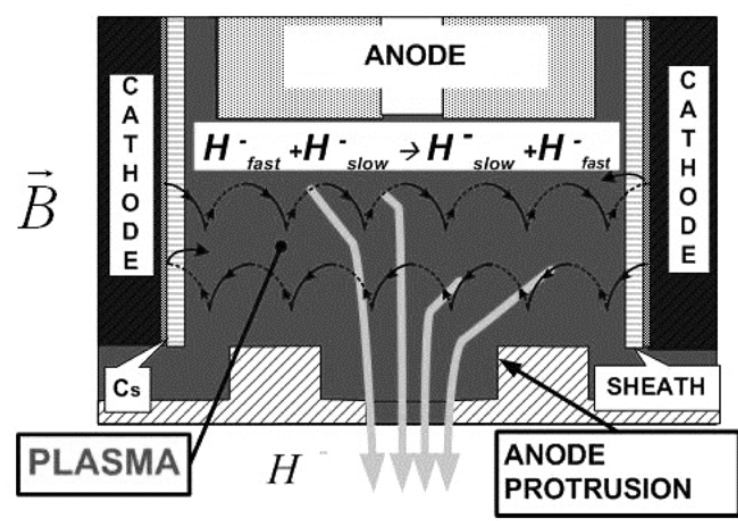

Fig. 5. Depiction of the surface plasma reactions including the role of cesium for both the (a) magnetron and (b) Penning configurations. External $B$ field direction is shown for the Penning configuration, for the Magnetron it is orthogonal to the electric field (see Fig. 7).

vertical emittance of $0.35 \pi \mathrm{mm}$-mrad (rms), which is unacceptably large. Because volume and surface production appear to produce different phase space profiles, this data may lend credence to the concept of time independent beam parameter mismatches presented in Section II-C. Further efforts to optimize the anode surface production while maintaining a lower emittance is under way.

\section{2) TRIUMF Cesiated Filament Multicusp $\mathrm{H}^{-}$} Source: Unique in the construction of the TRIUMF source [72] is the filter field which is produced by a permanent magnet array outside of the plasma on the cylindrical wall, see Fig. 4. The plasma in the discharge chamber, which is $10 \mathrm{~cm}$ in diameter, is confined with the usual cusp magnet arrangement (20 bar rows) and is heated by four half circle Ta filaments. This makes it possible to cancel out the $B$ fields on axis resulting in a reduced $E \times B$ drift which lowers the extracted electron current and increases the $\mathrm{H}^{-}$output.

Started in 1990 as a cesium free direct current (dc) source, this is the volume source which has been in accelerator service for the longest time. Recently, it was the model for sources made in Finland [73] and China [74]. Cesium was first added in 1998 and it now runs well in either mode [75]. After cesiation, an emittance drop from $\varepsilon_{n, 90 \%}=0.2$ to $0.13 \pi \mathrm{mm}$-mrad at 28 $\mathrm{keV}$ and a current of $20 \mathrm{~mA}$ was reported [76]. The maximum beam current increased with cesiation by a factor of 1.25 to 25 $\mathrm{mA} \mathrm{dc}$ with an emittance of $0.15 \pi \mathrm{mm}$-mrad. A drop in the already very low $\mathrm{e}^{-} / \mathrm{H}^{-}$ratio of $4-5$ was not reported. The extracted electrons are dumped into a gap at $25 \mathrm{kV}$.

By changing the magnet bar material from $\mathrm{SmCo}$ to $\mathrm{NdFeB}$ with a surface strength of $1.3 \mathrm{~T}$ and extending the source 10 $\mathrm{cm}$ an emittance of $0.1 \pi \mathrm{mm}-\mathrm{mrad}$ without Cs at $20 \mathrm{~mA} \mathrm{dc}$, 30-keV energy and 5-kW arc power was reported [75].

3) J-PARC Cesiated Filament Multicusp $\mathrm{H}^{-}$ Source: Another prototype volume source from JAERI [77], [78] is available for J-PARC. It has delivered 72 $\mathrm{mA}$ with a high df of $5 \%(1 \mathrm{msec} \times 50 \mathrm{~Hz})$ at $70 \mathrm{keV}$. This source is cesiated and a normalized rms emittance of $0.13(x) / 0.15(y) \pi$ mm-mrad was measured.

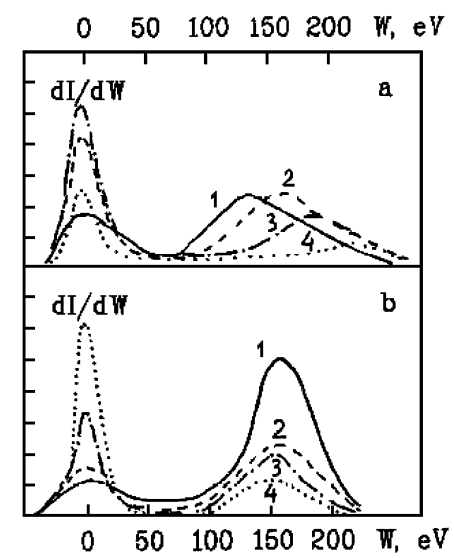

Fig. 6. Magnetron (in Russian: Planotron) energy spectra [85]. (a) For

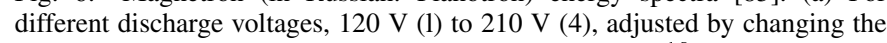
cesium flow. (b) For different gas injection rates, $1 \times 10^{16} \mathrm{~mol} / \mathrm{pulse}(1)$ to $2.2 \times 10^{16} \mathrm{~mol} /$ pulse (4). Charge exchange is optimized at the higher pressures.

\section{Surface Plasmas Sources}

$\mathrm{H}^{-}$Surface plasma sources (SPS) of the magnetron and penning geometries were first developed and cesiated in Novosibirsk, the former Soviet Union [79], where they achieved output current densities of several Amperes per square centimeter of aperture. The Magnetron concept was ultimately adopted by accelerator laboratories at Fermilab, Batavia,, IL, Argonne National Laboratory, Argonne, IL, and Brookhaven, Upton, NY, in the U.S. and DESY, Hamburg, Germany; while the Penning geometry was investigated at LANL, in the U.S., and is now utilized at ISIS, Didcot, U.K. Papers by Dudnikov [80], [81] discuss the history of $\mathrm{H}^{-}$SPS in more detail. Since the original conception of $\mathrm{H}^{-}$SPS many modifications and improvements have been made such that they constitute a mature and reliable technology today.

SPS sources rely on plasma surface reactions to produce negative ions (see Fig. 5). The cathode, typically molybdenum (Mo), is impacted by protons, heavy positive ions and energetic neutral atoms or molecules created in the plasma. As a result of 

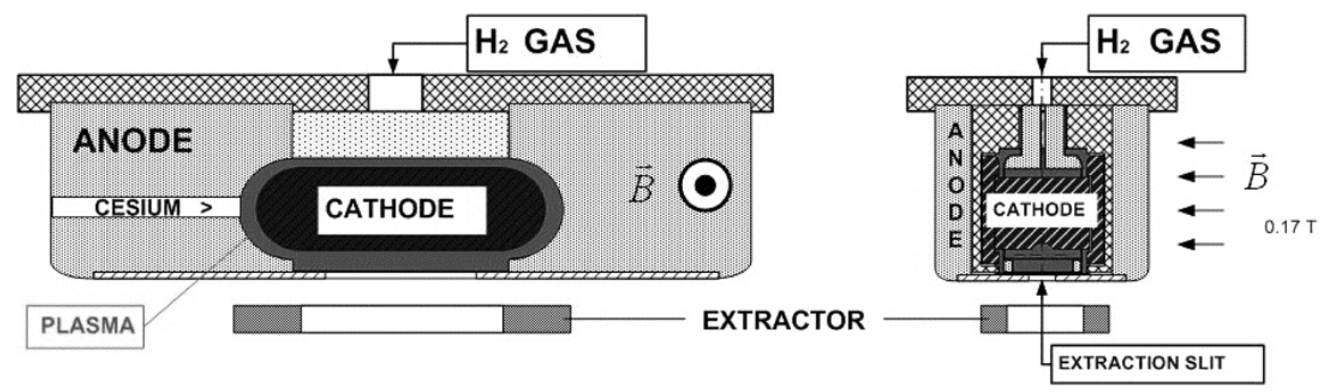

Fig. 7. Magnetron configuration of $\mathrm{H}^{-}$surface plasma sources.

these surface collisions, hydrogen atoms or protons desorbed or reflected from the cathode surface occasionally form $\mathrm{H}^{-}$ ions. Cesium is added to the source in order to lower the surface work-functions thereby improving the electron capture probability. At an optimal Cs coverage of approximately 0.6 monolayers, the work-function of Mo decreases from $4.6 \mathrm{eV}$ to about $1.5 \mathrm{eV}$; above this coverage the work-function rises to that of Cs approximately $1.8 \mathrm{eV}$ [82]. Cesium also plays a role in stabilizing the plasma by providing additional electrons. Negative ions produced at the cathode surface are accelerated across the plasma sheath. Once in the plasma, they can suffer electron detachment and be lost or undergo charge exchange, which is more prevalent once the $\mathrm{H}^{-}$ion enters the anode protrusion, see Fig. 5. In this region the electron density is reduced due to restricted diffusion across the magnetic field. These effects have been studied experimentally in the Penning SPS geometry [83], and in a multicusp volume source [84], while a theoretical treatment is found in [45]. Some $\mathrm{H}^{-}$ions may also be formed by surface production near the anode aperture. As a result of the different $\mathrm{H}^{-}$production mechanisms the extracted ion energy distribution has two distinct peaks in the magnetron geometry, see Fig. 6. The low energy peak is associated with slow ions formed in the anode protrusion via charge exchange or anode surface effects. The higher energy peak, around 100 $\mathrm{eV}$, corresponds to ions which are extracted directly from the cathode and have been accelerated through the cathode plasma sheath. Magnetrons are optimized on the high energy peak by running at low gas pressures thereby minimizing charge exchange while Penning sources are run at high gas pressure enhancing charge exchange, which results in a lower energy distribution.

The high-current density $\left(\sim 1 \mathrm{~A} / \mathrm{cm}^{2}\right)$ ion beams produced by these sources require strong focusing and/or rapid space charge neutralization. At $20-\mathrm{keV}$, a $100-\mathrm{mA} \mathrm{H}^{-}$beam diverges $\pm 250 \mathrm{mrad}$ within a few centimeters due to space charge defocusing [86]. Thus, apertures in the extraction region determine beam throughput and a large aperture system with strong focusing is required to collimate and accelerate the beam. HV electrostatic columns (Argonne and Fermilab) and more recently radio-frequency quadrupole (RFQs) (Brookhaven, DESY, and ISIS) have both been used successfully.

1) Magnetron SPS: In a magnetron, the discharge volume has a race track configuration with a central cold cathode biased by roughly $-100 \mathrm{~V}$ relative to the surrounding anode (see Fig. 7). A transverse magnetic field along the cathode axis of $1-1.5 \mathrm{kG}$ is applied, confining the plasma to an $E \times B$ drift around the race track. The minimum distance between the cathode and anode is approximately $1 \mathrm{~mm}$. Near the extraction region, a circular groove has been added to the cathode for geometric focusing of the $\mathrm{H}^{-}$ions produced on that surface. At Fermilab, this groove is approximately $1 \mathrm{~mm}$ deep and has been extended all the way around the cathode [36].

For magnetrons, $\mathrm{H}^{-}$extraction is typically at the space-charge limit with an extraction voltage of $35 \mathrm{kV}$ or less. Slit $(0.9 \mathrm{~mm} \times 10 \mathrm{~mm}$; Fermilab) and circular anode apertures $(2.8 \mathrm{~mm}$ in diameter; Brookhaven [87]) are both being used. The corresponding extraction systems are single acceleration gaps with magnetic focusing, either in the form of a double focusing sector magnet or a solenoid lens. These magnetic lens elements enable $\mathrm{H}^{-}$beam transport where the $\mathrm{H}^{-}$beam space charge is mostly compensated by accumulation of positive ions from background gas ionization. At Fermilab, Argonne, and DESY, a single electrode extraction system is in use coupled with a high-gradient $90^{\circ}$ bending magnet which serves to remove electrons and unwanted ions and to shape the $\mathrm{H}^{-}$ions into a suitable beam for acceleration. The energy resolution of this system is not sufficient to separate out the different $\mathrm{H}^{-}$energy peaks.

Magnetrons producing $\mathrm{H}^{-}$beams are operating with $0.5 \%$ duty factors or less. This limit is attributed to gas loading of the vacuum system and maintenance of the proper cesium coverage on the cathode surface, which is slowly sputtered away when the discharge is on. Operating in pulsed mode minimizes the gas load and maximizes the time cesium has to condense on the cathode surface. Gas injection is accomplished utilizing a piezoelectric valve, mounted close to the discharge area. With pulsed operation gas efficiencies of around $6 \%$ for the grooved cathode design have been achieved. An external boiler charged with liquid cesium is held between $70^{\circ} \mathrm{C}-150^{\circ} \mathrm{C}$ allowing cesium to continuously creep into the system. The cesium consumption at DESY is approximately $0.8 \mathrm{mg}$ per day at a plasma duty factor of $0.063 \%$. The consumption rates at the other accelerator labs are slightly higher, when scaled with df.

Magnetron lifetimes are on the order of 6-9 months and typically the sources are turned off for maintenance rather than failing. The principle failure modes are listed in [13] and include build up of cesium hydride near the gas inlet restricting gas flow and build up of Mo and Cs on the anode around the extraction aperture, which may dislodge limiting the aperture, shorting the cathode or impeding the plasma.

Operation of the BNL circular aperture SPS was recently summarized [88]. Typical operation parameters are an arc 


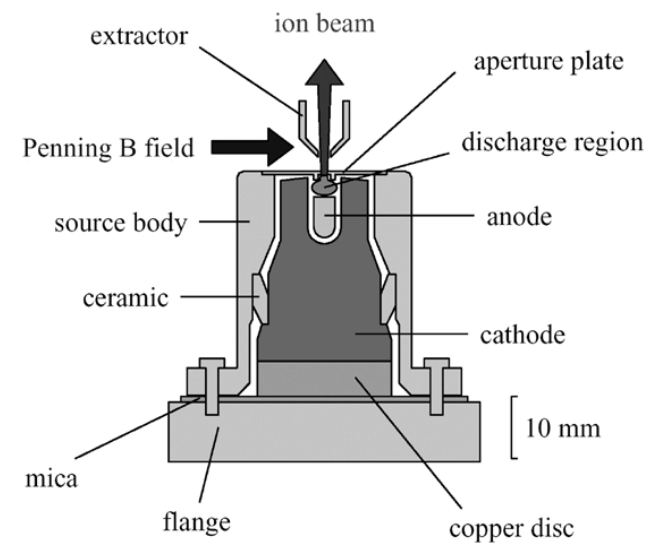

Fig. 8. Sectional view of the Penning SPS in use at RAL. (Reused with permission from J. W. G. Thomason, "A review of recent $\mathrm{H}^{-}$ion source work at Rutherford Appleton Laboratory," (ed), Conf. Proc. 639, 37 (2002). Copyright 2002, Amer. Inst. Phys,)

voltage of $V_{d}=-140$ to $-160 \mathrm{~V}$, arc currents of $I_{d}=8-18 \mathrm{~A}$, and a $0.5 \% \mathrm{df}(7.5 \mathrm{~Hz}, 700 \mu \mathrm{s})$. The extracted $\mathrm{H}^{-}$current is $90-100 \mathrm{~mA}$ at $35 \mathrm{keV}$. The source power efficiency was significantly improved when cathode geometrical focusing was introduced. The BNL SPS $\xi=50 \mathrm{~mA} / \mathrm{kW}$ is the highest of any operating accelerator $\mathrm{H}^{-}$source, and $\Gamma=0.5$. The $\mathrm{H}^{-}$beam emittance, after transport through a two-solenoid space-charge neutralized low energy beam transport system and acceleration to $750 \mathrm{keV}$ in a $200-\mathrm{MHz} \mathrm{RFQ}$, is $\varepsilon_{n, \mathrm{rms}}=0.4 \pi \mathrm{mm}$-mrad. Simple scaling of this magnetron suggests the $\mathrm{df}$ could be extended to $4.5 \%$, although lifetime reduction should be expected because of increased component wear.

2) Penning SPS: The Penning $\mathrm{H}^{-}$source is now being used at the Rutherford Appleton Laboratory (RAL), ISIS spallation neutron source [89], [90] and the Moscow Institute of Nuclear Research (INR) [91]. Fig. 8 shows a sectional view of the RAL $\mathrm{H}^{-}$Penning source with cathode, anode insert, discharge region, and ion beam extractor. Cesium metal flows from a 3 gram reservoir to the discharge from an external oven. The ISIS source operates at $50-\mathrm{Hz}, 200-\mu$ s beam $(1 \% \mathrm{df})$ while the discharge pulsewidth is $400-650 \mu$ s long (2\%-3.2\% df). The operating current is $45 \mathrm{~mA} \mathrm{H}^{-}$. While operating at this $\mathrm{df}$, the source lifetime is up to $40-50$ days. The beam is extracted from the plasma at $17 \mathrm{kV}$ through a $10 \times 0.6 \mathrm{~mm}^{2}$ slit. The beam is then transported by an $n=1,90^{\circ}$ dipole magnet with an $8 \mathrm{~cm}$ bending radius. The dipole magnet provides the magnetic field for the Penning discharge $(2.3 \mathrm{kG})$, coextracted electron suppression, separation of other negative ion impurities, and transforms the slit beam into a spatially round beam. Upon leaving the magnet box, the beam energy is increased to $35 \mathrm{keV}$. Recent RAL source development work [92] has led to rms normalized emittances of 0.62 and $0.73 \pi$ mm-mrad in the horizontal and vertical planes.

At INR [91], [93], the Penning $\mathrm{H}^{-}$source is used to produce a $100-\mathrm{Hz}, 200-\mu$ s beam pulse. The beam is extracted from a $15 \times 0.6 \mathrm{~mm}^{2}$ slit at $20 \mathrm{kV}$. For a $50-\mathrm{mA}$ beam with fluctuations, the normalized emittances in the $x$ and $y$ planes are 0.4 and 0.7 $\pi$ mm-mrad. No explicit mention is made of the beam fraction for these emittance values. INR notes that a quiescent mode for

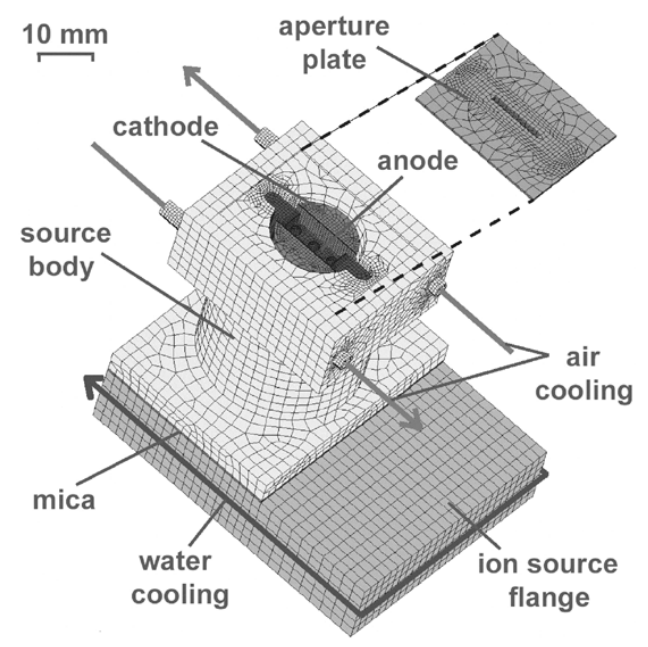

Fig. 9. Thermal analysis model for the RAL Penning source. (Reused with permission from D. C. Faircloth, "Advances in the Ion Source Research and Development Program at ISIS,” (ed), Conf. Proc., 243 (2005). Copyright 2005, Amer. Inst. Phys.)

Penning operation can be achieved at a peak current of $80 \mathrm{~mA}$ by reducing the magnetic field.

At LANL, the Penning $\mathrm{H}^{-}$source technology has been applied to numerous linac commissioning exercises [94], [95]. The first Penning experiments [96], [97] at LANL used a $10 \times 0.5$ $\mathrm{mm}^{2}$ emission slit at $0.5 \%(7 \mathrm{~Hz}, 0.7 \mathrm{~ms})$ to $2 \%(40 \mathrm{~Hz}, 0.5 \mathrm{~ms})$ df. These two pulsed modes gave $108 \mathrm{~mA}$ and $30-40 \mathrm{~mA} \mathrm{H}^{-}$ currents, respectively. For $100 \mathrm{~mA} \mathrm{H}{ }^{-}$beam, estimated (cf [97, Fig. 7(c)]) normalized rms emittances were $0.2 \pi \mathrm{mm}$-mrad and 0.03-0.04 $\pi \mathrm{mm}-\mathrm{mrad}$ in the long and narrow slit dimensions, respectively. Experiments with circular apertures [98] showed that a factor of three emittance reduction could be achieved with a factor of three reduction in the discharge voltage noise. For the low noise cases and $R=1.0 \mathrm{~mm}$, normalized emittances of 0.10 and $0.08 \pi \mathrm{mm}-\mathrm{mrad}$ were measured in the transverse planes for $35 \mathrm{~mA} \mathrm{H}^{-}$current at $15 \mathrm{keV}$ beam energy. The beam fraction for these emittances was $63 \%$.

The Penning source measurements discussed above use a $90^{\circ}$ bending magnet immediately following extraction. In 1983, a significant improvement in the SPS Penning technology occurred at LANL [34]. In order to reduce the $20-\mathrm{keV}$ beam transport length, the $90^{\circ}$ bending magnet was replaced with a permanent magnet assembly. This led to an $8.1^{\circ}$ bend for 22 $\mathrm{keV} \mathrm{H}^{-}$source that was named the small angle source (SAS). This step resulted in a slit emission source with 150-mA current at $0.5 \% \mathrm{df}$. The rms normalized emittances in the transverse planes were found to be $0.27 \pi$ mm-mrad and $0.04 \pi \mathrm{mm}-\mathrm{mrad}$ in the long and short slit dimensions, respectively. Subsequent circular aperture SAS development [99] with $R=1.25 \mathrm{~mm}$ gave rms normalized emittances of $0.053 \times 0.056 \pi \mathrm{mm}-\mathrm{mrad}$ in the transverse planes with $82 \mathrm{~mA} \mathrm{H}^{-}$current. The duty factor was $0.5 \%$.

An active area of research is to increase the Penning source df. For extended df operation, both RAL [92], [100] and LANL [101], [102] have pursued Penning source thermal analyzes with subsequent increase of internal source areas to reduce power flux density. This is especially critical for the cathode 
(a)

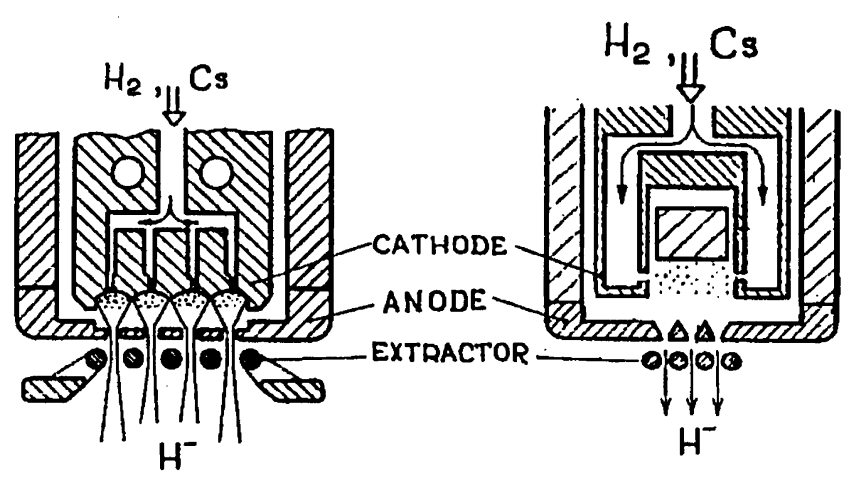

Fig. 10. Shows the cesiated SPS sources used to confirm anode production of $\mathrm{H}^{-}$ions where (a) is the honeycomb SPS with a mixture of cathode and anode $\mathrm{H}^{-}$production, while (b) is a hollow cathode Penning SPS where cesiated anode $\mathrm{H}^{-}$production is enforced. (Reused with permission from Yu. I. Belchenko, Rev. Sci. Instrum., 65, 1179 (1994). Copyright 1994, Amer. Inst. Phys.)

surface, where a pulsed temperature rise is thought to lead to a surface cesium imbalance resulting in discharge instabilities [34]. The thermal analysis model developed at RAL is shown in Fig. 9. This model has been validated by comparing temperature predictions to source measurements at typical source operating conditions. The RAL model has been extended to temperature increases associated with pulsed operation. The thermal analysis [92] has led to a proposed scaled source that should operate at $50 \mathrm{~Hz}$ with a $2 \mathrm{~ms}$ pulse length (10\% discharge df) at 4 $\mathrm{kW}$ instantaneous power to give the same cathode temperature rise as the standard RAL source. This implies $35 \mathrm{~mA}$ of $\mathrm{H}^{-}$ current from a slit emitter at the extended df. One scaled up LANL source (the $4 \times$ source) [101] was aggressively cooled, and was operated successfully in discharge-only mode with a $4 \mathrm{~ms}$ pulse length at $15 \mathrm{~Hz}(6 \% \mathrm{df})$. A request by the ESS community [103] to apply the Penning scaling laws to study the feasibility of $100-\mathrm{mA}$ accelerator quality $\mathrm{H}^{-}$beam was made in 2001. It was concluded [104] that using a slit extraction system a 4X scaled Penning should reach 100-mA current with $\varepsilon_{n, \mathrm{rms}}<0.3 \pi \mathrm{mm}$-mrad in both transverse planes at $5 \% \mathrm{df}$ (50 Hz, $1 \mathrm{~ms})$.

3) Hollow-Cathode Penning SPS: The Budker Institute of Nuclear Physics (BINP) is developing a dc version [105], [106] of the Penning source using hollow-cathodes. $\mathrm{H}^{-}$currents up to $8 \mathrm{~mA}$ at $25 \mathrm{kV}$ are obtained using a 3 -mm-diameter aperture. Emittance measurements give rms normalized emittances of $0.2 \pi \mathrm{mm}$-mrad along the magnetic field and $0.3 \pi \mathrm{mm}-\mathrm{mrad}$ across the magnetic field. The BINP development emphasizes $\mathrm{H}^{-}$production at the cesiated anode surfaces [107], [108].

Convincing experimental evidence for anode production in cesiated SPS is described in [108]. Fig. 10 shows two SPS sources investigated at BINP. On the left [Fig. 10(a)] is a multiaperture honeycomb SPS with a movable emission plate. This honeycomb SPS has 120 matched geometrical focused cathode indentations and anode emission apertures. The total negative ion current was found to be a sum of currents produced at the cathode and the anode emission apertures. Anode $\mathrm{H}^{-}$production was deduced to be about $20 \%$ of the total negative ion current. The high anode $\mathrm{H}^{-}$production led to the

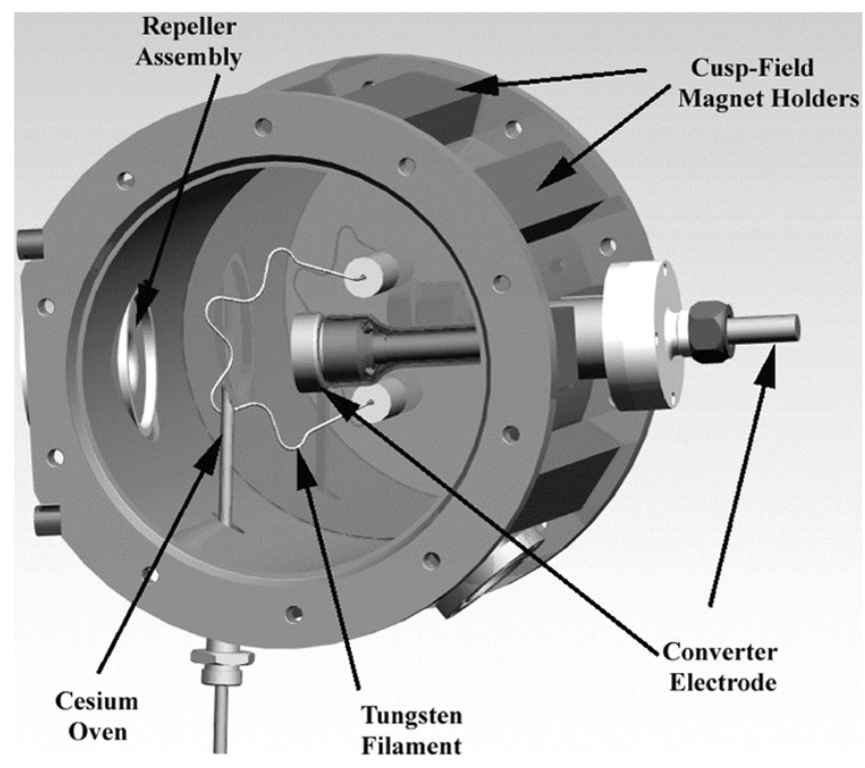

Fig. 11. LANSCE $\mathrm{H}^{-}$surface converter source.

construction of the hollow cathode Penning source shown in Fig. 10(b). This geometry enforces anode production, and the reported $\xi=35 \mathrm{~mA} / \mathrm{kW}$ is three times lower than that of the honeycomb SPS. Unlike cathode production, anode produced $\mathrm{H}^{-}$may be directly extracted, or $\mathrm{H}^{-}$ions with trajectories away from the emission aperture may undergo charge exchange reactions with atomic hydrogen in the near anode plasma volume. These latter $\mathrm{H}^{-}$ions may then be extracted.

\section{Surface Converter Source}

The $\mathrm{H}^{-}$surface converter source was developed for accelerator applications at LANL [42], [43], and at the National Laboratory for High Energy Physics (KEK), Tsukuba, Japan [109] in the early $1980 \mathrm{~s}$, but was based on a $\mathrm{H}^{-}$source originally developed for fusion energy applications [110], [111]. A 3-D view of the LANSCE H${ }^{-}$production source is shown in Fig. 11. Plasma is generated in $\mathrm{H}_{2}$ by thermionic electrons from filaments or $\mathrm{LaB}_{6}$ cathodes. The plasma is confined by a multicusp magnetic field. The converter electrode is biased to several hundred volts negative relative to the ion source cylindrical containment vessel. Positive ions and neutrals strike the cesiated molybdenum converter surface and may form $\mathrm{H}^{-}$ions by either charge-exchange or sputtering $\mathrm{H}^{-}$ions from the converter surface [112]. $\mathrm{H}^{-}$ions are accelerated away from the converter surface, pass through the repeller aperture to the emission aperture, and are subsequently accelerated to injector energies. The function of the repeller is to reduce extracted electron currents by combined electric and magnetic fields. If all $\mathrm{H}^{-}$ions which reach the emission aperture originate at the converter, the upper limit of the source's emittance may be estimated from the internal geometry of converter, repeller, and emitter radii, and the separation of these apertures.

1) Lansce Surface Converter Source: The LANSCE operational source runs on a $24 \mathrm{~h} /$ day, 28 day $(672 \mathrm{~h})$ operational cycle at $10 \%-12 \%$ df. The $800-\mathrm{MeV}$ accelerator operates at $120 \mathrm{~Hz}$ with nominal 1-ms beam pulses, serving a variety of 
TABLE I

List OF ACCElERATOR H ION SOURCES AlONG With THE RELEVANT Parameter Space Discussed Within This ReVIEW. TyPical $\mathrm{I}_{H}{ }^{-}$ Currents ARE Given With an Associated EmitTance. [13], [14] Were USED to Fill in VALUES NOT PREVIOUSLy CiTED. UNDERLINED PARAMETERS ARE FROM [13] AND BRACKETED PARAMETERS ARE FROM [14]

\begin{tabular}{|c|c|c|c|c|c|c|c|c|}
\hline $\begin{array}{l}\text { Source } \\
\text { Type } \\
\text { (drive) }\end{array}$ & $\begin{array}{l}\text { Source } \\
\text { Location }\end{array}$ & $\begin{array}{l}\mathrm{I}_{\mathrm{H}} \\
\text { (ma) }\end{array}$ & $\begin{array}{l}\text { Beam } \\
\text { df } \\
(\%)\end{array}$ & $\begin{array}{l}\text { Rep. } \\
\text { Rate } \\
(\mathrm{Hz}) \\
\end{array}$ & $\begin{array}{l}\varepsilon_{\mathrm{n}, \mathrm{ms}} \mathrm{x} / \mathrm{y} \\
(\pi \mathrm{mm}-\mathrm{mrad})\end{array}$ & $\begin{array}{c}\mathrm{P}_{\mathrm{d}} \\
(\mathrm{kW})\end{array}$ & $\mathrm{e} / \mathrm{H}^{-}$ & $\begin{array}{l}\text { Life- } \\
\text { time } \\
\text { (month) }\end{array}$ \\
\hline \multicolumn{9}{|l|}{$\begin{array}{l}\text { Multicusp } \\
\text { Volume, } \mathrm{H}_{2}\end{array}$} \\
\hline $\mathrm{RF}$ & $\begin{array}{l}\text { DESY } \\
\text { (HERA) }\end{array}$ & 40 & 0.12 & $\underline{8}$ & 0.25 & $\simeq 20$ & 26 & $>12$ \\
\hline $\mathrm{LaB}_{6}$ fil. & $\begin{array}{l}\text { J-PARC } \\
(\mathrm{KEK})\end{array}$ & 38 & 0.9 & 25 & & 35 & & \\
\hline \multicolumn{9}{|l|}{$\begin{array}{l}\text { Multicusp } \\
\text { Volume, } \\
\mathrm{Cs}+\mathrm{H}_{2}\end{array}$} \\
\hline $\mathrm{RF}$ & SNS & 33 & 6.0 & 60 & $0.22 / 0.18$ & $\sim 40$ & & \\
\hline W fil. & TRIUMF & 20 & 100 & $\mathrm{dc}$ & 0.022 & $\sim 5$ & $4-5$ & $\sim ?$ \\
\hline W fil. & $\begin{array}{l}\text { J-PARC } \\
\text { (JAERI) }\end{array}$ & 72 & 5.0 & 50 & $0.13 / 0.15$ & & & \\
\hline \multicolumn{9}{|l|}{ SPS } \\
\hline \multirow[t]{2}{*}{ Magnetron } & BNL & 100 & 0.5 & 7.5 & 0.4 & $\sim 2$ & 0.5 & $\simeq 6$ \\
\hline & $\begin{array}{l}\text { Fermilab } \\
\text { DESY }\end{array}$ & $\begin{array}{c}60 \\
50\end{array}$ & $\begin{array}{l}0.1 \\
0.05\end{array}$ & $\begin{array}{r}15 \\
6\end{array}$ & $\begin{array}{c}0.2 / 0.3 \\
0.46 / 0.31\end{array}$ & $\begin{array}{c}\sim 7 \\
\{\sim 5\}\end{array}$ & & $\begin{array}{l}\sim 6 \\
\sim 9 \\
\sim 9\end{array}$ \\
\hline Penning & $\begin{array}{l}\text { ISIS } \\
\text { INR }\end{array}$ & $\begin{array}{l}45 \\
50\end{array}$ & $\begin{array}{l}1.0 \\
2.0\end{array}$ & $\begin{array}{r}50 \\
100\end{array}$ & $\begin{array}{c}0.6 / 0.7 \\
0.4 / 0.7\left(\varepsilon_{0}\right)\end{array}$ & $\left\{\sim \frac{\sim}{\{10\}}\right.$ & & $\begin{array}{l}\sim 2 \\
\sim 0.5\end{array}$ \\
\hline Hollow cath. & BINP & 8 & 100 & $\mathrm{dc}$ & $0.2 / 0.3$ & 0.4 & & $\overline{-0.2}$ \\
\hline $\begin{array}{l}\text { Converter } \\
\text { (W fil.) }\end{array}$ & LANSCE & 17 & 12.0 & 120 & 0.13 & $\sim 6$ & 2.5 & $\overline{\sim 1}$ \\
\hline ( $\mathrm{LaB}_{6}$ fil. $)$ & KEK & 20 & 0.5 & 20 & 0.33 & $\sim 4$ & 4.5 & $3-4$ \\
\hline
\end{tabular}

TABLE II

DESIRED BEAm PARAMETERS OF Future ACCElERATORS. DATA ADAPTED FROM [13]

\begin{tabular}{|c|c|c|c|c|c|}
\hline $\begin{array}{l}\text { Accelerator } \\
\text { Designation }\end{array}$ & $\begin{array}{c}\mathrm{I}_{\mathrm{H}^{-}} \\
(\mathrm{ma})\end{array}$ & $\begin{array}{l}\text { Pulse } \\
\text { Length } \\
(\mathrm{ms})\end{array}$ & $\begin{array}{l}\text { Rep. } \\
\text { Rate } \\
(\mathrm{Hz})\end{array}$ & $\begin{array}{l}\text { Beam } \\
\text { df } \\
(\%)\end{array}$ & $\begin{array}{l}\varepsilon_{\mathrm{n}, \mathrm{rms}} \mathrm{x} / \mathrm{y} \\
(\pi \mathrm{mm}- \\
\mathrm{mrad})\end{array}$ \\
\hline ESS [117] & 70 & 1.2 & 50 & 6 & 0.3 \\
\hline $\begin{array}{l}\text { CERN-SPL } \\
\text { Phase2 [118] }\end{array}$ & 30 & 2.8 & 50 & 14 & 0.2 \\
\hline SNS [67] & 50 & 1 & 60 & 6 & 0.2 \\
\hline J-PARC [119] & 50 & 0.5 & 50 & 2.5 & 0.3 \\
\hline $\begin{array}{l}\text { FNAL Proton } \\
\text { Driver }[120,121]\end{array}$ & $12 / 33$ & $1 / 3$ & $10 / 2.5$ & $1 / 0.7$ & 0.2 \\
\hline $\begin{array}{l}\text { LANSCE Upgrade } \\
{[122]}\end{array}$ & 40 & 1.0 & 120 & 12 & $0.13 / 0.13$ \\
\hline
\end{tabular}

user programs. Over the last few years, the $\mathrm{H}^{-}$source reliability has been high with the source failing once in 18 operational cycles [113]. The cusp field magnets are made of SmCo with $3.4 \mathrm{kG}$ fields at contact. Typical source operation is at a pulsed discharge of $V_{d}=-180 \mathrm{~V}$, which gives 30-40 A of discharge current, depending on the tungsten filament heating current. The 1.5-mm-diameter tungsten filaments have a complex shape, shown in Fig. 11. The lifetime-limiting source components are the tungsten filaments. The surface converter electrode operates in the -250 to $-300 \mathrm{~V}$ range. The $\mathrm{H}^{-}$beam current is typically $16-18 \mathrm{~mA}$ at $80-\mathrm{keV}$, and $\Gamma=2.5$. With the $10-\mathrm{mm}$ emission aperture, the laboratory beam emittance is about 70 $\pi$ mm-mrad at $95 \%$ beam fraction, which corresponds to about $\varepsilon_{n, \mathrm{rms}}=0.13 \pi \mathrm{mm}-\mathrm{mrad}$ for $16-18 \mathrm{~mA}$ of current. A collaborative upgrade program between LBNL and LANSCE on this source did lead to $40-\mathrm{mA}$ of $\mathrm{H}^{-}$current, but unacceptably large emittance growth, $\varepsilon_{n, \mathrm{rms}}=0.3-0.4 \pi \mathrm{mm}-\mathrm{mrad}$, was found at the higher current [113], [114]. The LANSCE $\mathrm{H}^{-}$source development is moving in the direction of creating a $25-\mathrm{mA} \mathrm{H}^{-}$ source at $12 \%$ df with minimal emittance growth [44], [115] while maintaining the 28 day operational cycle.
2) KEK Surface Converter Source: An $\mathrm{H}^{-}$surface converter source has been used on the KEK synchrotron [109], [116] since 1985. The KEK surface converter source is similar to Fig. 11, except $\mathrm{LaB}_{6}$ is used for the filament material. Typical discharge conditions are $V_{d}=-100$ to $-150 \mathrm{~V}$ producing 25-30 A of discharge current from two $\mathrm{LaB}_{6}$ filaments. The filament currents are $130 \mathrm{~A}$. While operating with 1.2 and 1.5 $\mathrm{mm}$ diameter tungsten filaments, the source lifetime was 200 to $300 \mathrm{~h}$. The $\mathrm{LaB}_{6}$ filaments have extended the source lifetime to $2600 \mathrm{~h}$. The source df is $0.5 \%(20 \mathrm{~Hz}, 250 \mu \mathrm{s})$. The converter is typically operated at $-500 \mathrm{~V} . \mathrm{H}^{-}$current to the linac is $15-20$ $\mathrm{mA}$ with about $90 \mathrm{~mA}$ of extracted electrons, giving $\Gamma=4.5$. The $\mathrm{H}^{-}$beam is immediately accelerated to $750 \mathrm{keV}$, where the normalized emittance is $1.8-2.1 \pi \mathrm{mm}-\mathrm{mrad}$ at $F=0.9$. Using (3), this gives an estimate of $\varepsilon_{n, \mathrm{rms}}=0.3-0.35 \pi \mathrm{mm}-\mathrm{mrad}$.

\section{SUMMARY}

Within this paper, the basic technical issues $\mathrm{H}^{-}$ion sources address in order to provide usable beams for acceleration have been presented. In addition, a summary of a number of $\mathrm{H}^{-}$ sources currently in use at accelerator laboratories around the world has been presented. Table I represents a compilation of some of the relevant parameter space. Although key to most applications, intensity is no longer the sole factor in source selection. Beams with low emittance at all intensities and duty factors are necessary. In addition source lifetime and redundancy is important in reducing laboratory down time. The demands of future facilities follow this trend while requesting longer pulse lengths and higher duty factors with currents ranging from 12-65 mA. Table II presents desired beam parameters of possible future facilities.

\section{REFERENCES}

[1] K. Prelec and T. Sluyters, "Formation of negative hydrogen ions in direct extraction sources," Rev. Sci. Instrum., vol. 44, no. 10, pp. 1451-1463, Jan. 1973.

[2] K. Prelec, Ed., Procceedings of the Symposium on the Production and Neutralization of Negative Hydrogen Ions and Beams. Upton, NY: Brookhaven Nat. Lab. 50 727, 1977.

[3] T. Sluyters, Ed., Proceedings of the 2nd International Symposium on the Production and Neutralization of Negative Hydrogen Ions and Beams. Upton, NY: Brookhaven Nat. Lab. 51 304, 1980.

[4] K. Prelec, Ed., Proceedings of the 3rd International Symposium on the Production and Neutralization of Negative Hydrogen Ions and Beams. ser. AIP Conf. Proc. New York: Amer. Inst. Phys., 1983, vol. 111.

[5] J. G. Alessi, Ed., Proceedings of the 4th International Symposium on the Production and Neutralization of Negative Hydrogen Ions and Beams. ser. AIP Conf. Proc.. New York: Amer. Inst. Phys., 1986, vol. 158.

[6] A. Hershcovitch, Ed., Proceedings of the 5th International Symposium on the Production and Neutralization of Negative Hydrogen Ions and Beams. ser. AIP Conf. Proc.. New York: Amer. Inst. Phys., 1990, vol. 210.

[7] J. G. Alessi and A. Hershcovitch, Eds., Proceedings of the 6th Inter national Symposium on the Production and Neutralization of Negative Hydrogen Ions and Beams. New York: Amer. Inst. Phys., 1992, vol. 287, sec. AIP Conf. Proc..

[8] K. Prelec, Ed., Proceedings of the 7th International Symposium on the Production and Neutralization of Negative Hydrogen Ions and Beams. ser. AIP Conf. Proc.. New York: Amer. Inst. Phys., 1995, vol. 380.

[9] C. W. Schmidt, "Review of negative hydrogen ion sources," in Proc. Linear Accel. Conf., , 1990, LA-12 004-C, pp. 259-259.

[10] R. Keller, "Ion source and low-energy beam transport issues for $\mathrm{H}^{-}$ accelerators," in Proc. Particle Accel. Conf., vol. 1, 1999, pp. 87-87. 
[11] J. Peters, "New developments in rf and filament-volume $\mathrm{H}^{-}$sources for accelerators," Rev. Sci. Instrum., vol. 75, no. 5, pp. 1709-1713, May 2004.

[12] H. Zhang, Ion Sources. Beijing, China: Science Press, 1999, ch. 8.

[13] R. Scrivens, "Proton and ion sources for high intensity accelerators," presented at the Proc. Eur. Particle Accel. Conf., Lucerne, Switzerland, Jul. 5-9, 2004, pp. 103-107.

[14] R. F. Welton, "Overview of high-brightness $\mathrm{H}^{-}$ion sources," in Proc. Inter. Linac Conf., Gyeongju, Korea, Aug. 19-23, 2002, pp. 559-559.

[15] J. Peters, "Review of negative hydrogen high brightness/high current ion source," in Proc. LINAC, 1998.

[16] J. D. Sherman and G. Rouleau, "New developments with $\mathrm{H}^{-}$sources," in Proc. 17th Int. Conf. Appl. Accel. Res. Industry, Denton, TX, 2002, pp. $1038-1038$.

[17] C. Lejeune and J. Aubert, "Emittance and brightness: Definitions and measurements," in Advances in Electronics and Electron Physics, Supplement 13A, Applied Charged Particle Optics Part A, A. Septier, Ed. New York: Academic, 1980, pp. 159-159.

[18] R. Keller, "High-current gaseous ion sources," in The Physics and Technology of Ion Sources, G. Brown, Ed. New York: Wiley, 1989, pp. 30-31.

[19] F. J. Sacherer, "RMS envelope equations with space charge," IEEE Trans. Nucl. Sci., vol. 18, no. 3, pp. 1105-1107, Jun. 1971.

[20] T. Wangler, Principles of RF linear accelerators. New York: Wiley, 1998, pp. 261-263.

[21] P. Allison, J. D. Sherman, and H. V. Smith, Jr., "Comparison of Measured Emittance of an $\mathrm{H}^{-}$ion Beam With a Simple Theory," Los Alamos Nat. Lab., Los Alamos, NM, Tech. Rep. LA-8808-MS, 1981.

[22] P. Allison, "Some comments on emittance of $\mathrm{H}^{-}$ion beams," . ser. AIP Conf. Proc., J. Alessi, Ed. New York: Amer. Inst. Phys., 1986, vol. 158, pp. $465-465$.

[23] M. Frank and L. Rybarcyk, "Beam dynamics simulations of the lansce linac," in Proc. LINAC, 1998, pp. 839-841.

[24] M. P. Stockli, R. F. Welton, R. Keller, A. P. Letchford, R. W. Thomae, and J. W. G. Thomason, "Accurate estimation of the RMS emittance from single current amplifier data," . ser. AIP Conf. Proc., M. P. Stockli, Ed. New York: Amer. Inst. Phys., 2002, vol. 639, pp. 135-159.

[25] R. F. Welton, M. P. Stockli, R. Keller, R. W. Thomae, J. Thomason, J. Sherman, and J. Alessi, "Emittance characteristics of high-brightness $\mathrm{H}^{-}$ion sources," . ser. AIP Conf. Proc., M. P. Stockli, Ed. New York: Amer. Inst. Phys., 2002, vol. 639, pp. 160-174.

[26] M. P. Stockli, M. Leitner, D. P. Moehs, R. Keller, and R. F. Welton, "Beam dumping ghost signals in electric sweep scanners," . ser. AIP Conf. Proc., J. D. Sherman and Yu. I. Belchenko, Eds. New York: Amer. Inst. Phys., 2004, vol. 763, pp. 145-145.

[27] P. W. Allison, J. D. Sherman, and D. B. Holtkamp, "An emittance scanner for intense low-energy ion beams," IEEE Trans. Nucl. Sci., vol. 30, no. 4, pp. 2204-2206, Aug. 1983.

[28] J. D. Lawson, The Physcis of Charged Particle Beams, 2nd ed. Oxford: Clarendon Press, 1988, pp. 200-200.

[29] M. Bacal, "Photodetachment diagnostic techniques for measuring negative ion densities and temperatures in plasmas," Rev. Sci. Instrum., vol. 71, no. 11, pp. 3981-4006, Nov. 2000.

[30] A. A. Ivanov, Jr., "Two negative ion groups in volume $\mathrm{H}^{-}$sources," Rev. Sci. Instrum., vol. 75, no. 5, pp. 1754-1756, May 2004.

[31] M. Bacal, A. Hatayama, and J. Peters, "Volume production negative ion sources," IEEE Trans. Plasma Sci., vol. 33, no. 6, pp. 1845-1871, Dec. 2005.

[32] J. D. Sherman, H. V. Smith Jr, C. Geisik, and P. Allison, "H- temperature measurements by a slit diagnostic technique," Rev. Sci. Instrum., vol. 62, no. 10, pp. 2314-2317, Oct. 1991.

[33] H. V. Smith Jr, J. D. Sherman, C. Geisik, and P. Allison, "H- temperature dependencies in a penning surface-plasma source," Rev. Sci. Instrum., vol. 63, no. 4, pp. 2723-2725, Apr. 1992.

[34] G. E. Derevyankin and V. G. Dudnikov, "Production of high brightness $\mathrm{H}^{-}$beams in surface plasma sources," . ser. AIP Conf. Proc., K. Prelec, Ed. New York: Amer. Inst. Phys., 1983, vol. 111, pp. 376-397.

[35] P. Allison and J. D. Sherman, "Operating experience with a 100-keV, 100-mA H- injector," . ser. AIP Conf. Proc., K. Prelec, Ed. New York: Amer. Inst. Phys., 1983, vol. 111, pp. 511-519.

[36] D. P. Moehs, "Studies on a magnetron source," in Amer. Inst. Phys., ser. AIP Conf. Proc., M. P. Stockli, Ed. New York, 2002, vol. 639, pp. $115-127$.

[37] I. A. Soloshenko, "Space charge compensation and collective processes in the intensive beams of $\mathrm{H}^{-}$ions," . ser. AIP Conf. Proc., K. Prelec, Ed. New York: Amer. Inst. Phys., 1995, vol. 380, pp. 345-364.
[38] P. Allison, "Emittance growth caused by current variation in a beam transport channel," IEEE Trans. Nucl. Sci., vol. NS-32, pp. 2556-2558, Oct. 1985.

[39] J. Guyard and M. Weiss, "Use of beam emittance measurements in matching problems," in Proc. Int. Linear Accel. Conf., Chalk River, ON, Canada, 1976, AECL-5677, pp. 254-254.

[40] Brookhaven Nat. Lab. 51 304, T. Sluyters, Ed., Upton, NY, 1980, pp. 137-144.

[41] Brookhaven Nat. Lab. 51 304, T. Sluyters, Ed., Upton, NY, 1980, pp. 153-159.

[42] R. R. Stevens, Jr., R. L. York, J. R. M. York, and R. Kandarian, "Status of the new high intensity $\mathrm{H}^{-}$injector at LAMPF," in Proc. Linear Accel. Conf., Seeheim, Germany, 1984, GSI-84-11, pp. 226-228.

[43] R. L. York, R. R. Stevens Jr, R. A. DeHaven, J. R. McConnell, E. P. Chamberlin, and R. Kandarian, Nucl. Instrum. Meth. Phys. Res., vol. B10/11, pp. 891-895, May 1985.

[44] J. Sherman, E. Chacon-Golcher, E. G. Geros, E. Jacobson, P. Lara, B. J. Meyer, P. Naffziger, G. Rouleau, S. C. Schaller, R. R. Stevens, Jr., and T. Zaugg, "Physical insights and test stand results for the LANSCE Hsurface converter source," . ser. AIP Conf. Proc., J. D. Sherman and Yu. I. Belchenko, Eds. New York: Amer. Inst. Phys., 2004, vol. 763, pp. 254-266.

[45] T. Sakurabayashi, A. Hatayama, and M. Bacal, "Effects of transverse magnetic field and spatial potential on negative ion transport in negative ion sources," . ser. AIP Conf. Proc., J. D. Sherman and Yu. I. Belchenko, Eds. New York: Amer. Inst. Phys., 2004, vol. 763, pp. 96-106.

[46] E. Chacon-Golcher, K. J. Bowers, and J. D. Sherman, "Progress in the computer simulation of LANSCE's production $\mathrm{H}^{-}$source," presented at the Proc. Eur. Conf. Plasma Phys., London, U.K., Jun. 28-Jul. 22004.

[47] D. Riz and J. Pamela, "Modeling of negative ion transport in a plasma," Rev. Sci. Instrum., vol. 69, no. 2, pp. 914-919, Feb. 1998.

[48] M. A. Leitner, D. C. Wutte, and K. N. Leung, "2D simulation and optimization of the volume $\mathrm{H}^{-}$ion source extraction system for the spallation neutron source accelerator," Nucl. Instrum. Meth. Phys. Res., vol. A427, pp. 242-249, May 1999.

[49] P. Spaedtke, "Sophisticated computer simulation of ion beam extraction for different types of plasma generators," Rev. Sci. Instrum., vol. 75, no. 5, pp. 1643-1645, May 2004.

[50] (2000, Oct.) Thunderbird Simulations, PBGUNS Version 5.0. [Online]. Available: www.thunderbirdsimulations.com

[51] R. F. Welton, M. P. Stockli, J. E. Boers, R. Rauniyar, R. Keller, J. W. Staples, and R. W. Thomae, "Simulation of the ion source extraction and low energy beam transport systems for the spallation neutron source," Rev. Sci. Instrum., vol. 73, no. 2, pp. 1013-1016, Feb. 2002.

[52] R. Becker, "Self-consistent multicomponent plasma sheath theory for the extraction of $\mathrm{H}^{-}$ions," Rev. Sci. Instrum., vol. 75, no. 5, pp. 1687-1693, May 2004.

[53] — "Mathematical formulation and numerical modeling of the extraction of $\mathrm{H}^{-}$ions," in Proc. AIP Conf., 2004, pp. 194-194.

[54] B. Herrmannsfeldt, G. Herrmannsfeldt, R. Becker, O. Kester, B. Zipfel, and J. G. Becker. Space Charge Particle Optics. [Online]. Available: http://www.egun-igun.com

[55] C. F. Chan, W. S. Cooper, J. W. Kwan, and W. F. Steele, "Dynamics of skew beams and the projectional emittance," Nucl. Instrum. Meth. Phys. Res., vol. A306, pp. 112-122, Aug. 1991.

[56] M. Sarstedt, "Section]al and projectional emittance measurements," Rev. Sci. Instrum., vol. 67, no. 4, pp. 1653-1656, Apr. 1996.

[57] N. Pichoff, "Some Words About the Comparison Between the Radial and Axial Emittance,", Saclay, France, Tech. Note, CEA/LNS/GECA.

[58] J. Peters, "Entwicklung und optimierung einer HF- "volume" quelle zur erzeugung von $\mathrm{H}^{-}$loner für hera," Ph.D. dissertation, Universität Frankfurt, Frankfurt, Germany, 2001.

[59] - "Internal versus external RF coupling into a volume source," in Proc. Eur. Particle Accel. Conf., La Villette, France, Jun. 3-7, 2002, pp. 1727-1729.

[60] - "The status of DESY H- sources," in Proc. Int. Linear Accel. Conf., Monterey, Canada, Aug. 21-25, 2000, pp. 217-219.

[61] - "The new HE RA H- RF volume source," in Proc. Int. Linear Acc. Conf., Gyeongju, Korea, Aug. 19-23, 2002, pp. 422-424.

[62] J. R. Hiskes and A. M. Karo, "Generation of negative ions in tandem high-density hydrogen discharges," J. Appl. Phys., vol. 56, no. 7, pp. 1927-1938, Oct. 1984.

[63] A. Ueno, private communication, 2005.

[64] A. Ueno, K. Ikegami, and Y. Kondo, "Surface production dominating Cs-free $\mathrm{H}^{-}$ion source for high intensity and high energy proton accelerators," Rev. Sci. Instrum., vol. 75, no. 5, pp. 1714-1719, May 2004. 
[65] S. Henderson, A. Aleksandrov, S. Assadi, W. Blokland, P. Chu, S. Cousineau, V. Danilov, G. Dodson, J. Galambos, M. Giannella, D. Jeon, L. Kravchuk, S. Kim, M. Stockli, E. Tanke, R. Welton, and T. Williams, "SNS beam commissioning status," in Proc. Eur. Particle Accel. Conf., Lucerne, Switzerland, Jul. 5-9, 2004, pp. 1524-1526.

[66] R. F. Welton, M. P. Stockli, S. N. Murray, and R. Keller, "Development and status of the SNS ion source," in Proc. Particle Accel. Conf., vol. 5, May 12-16, 2003, pp. 3306-3308.

[67] R. Keller, D. Cheng, R. Digennaro, R. A. Gough, J. Greer, K. N. Leung, A. Ratti, J. Reijonen, R. W. Thomae, T. Schenkel, J. W. Staples, and R. Yourd, "Ion-source and low-rnergy beam-transport issues with the front-end systems for the spallation neutron source," Rev. Sci. Instrum., vol. 73, no. 2, pp. 914-916, Feb. 2002.

[68] R. F. Welton, M. P. Stockli, Y. Kang, M. Janney, R. Keller, R. W. Thomae, T. Schenkel, and S. Shukla, "Ion source antenna development for the spallation neutron source," Rev. Sci. Instrum., vol. 73, no. 2, pp. 1008-1012, Feb. 2004.

[69] R. F. Welton, M. P. Stockli, M. Forrette, C. Williams, R. Keller, and R. W. Thomae, "Enhancing surface ionization and beam formation in volume-type $\mathrm{H}^{-}$ion sources," in Proc. Eur. Particle Accel. Conf., La Villette, France, Jun. 3-7, 2002, pp. 635-637.

[70] R. F. Welton, M. P. Stockli, S. N. Murray, and R. Keller, "Recent advances in the performance and understanding of the SNS ion source,". ser. AIP Conf. Proc., J. D. Sherman and Yu. I. Belchenko, Eds. New York: Amer. Inst. Phys., 2004, vol. 763, pp. 296-314.

[71] M. Stockli and D. Moehs, private communication, 2005.

[72] T. Kuo, D. Yuan, K. Jayamanna, M. McDonald, R. Baartman, P. Schmor, and G. Dutto, "On the development of a $15 \mathrm{~mA}$ direct current $\mathrm{H}^{-}$multicusp source," Rev. Sci. Instrum., vol. 67, no. 3, pp. 1314-1316, Mar. 1996.

[73] T. Kuo, R. Baartman, G. Dutto, S. Hahto, J. Arje, and E. Liukkonen, "A high intensity dc $\mathrm{H}^{-}$source for low energy injection," Rev. Sci. Instrum., vol. 73, no. 2, pp. 986-988, Feb. 2002.

[74] T. Zhang, Z. Li, C. Chu, L. Wu, J. Zhong, C. Jiao, T. Ge, G. Pan, and F. Guan, "H- cusp source development for $100 \mathrm{MeV}$ compact cyclotron at china institute of atomic energy," Rev. Sci. Instrum., vol. 75, no. 5, pp. 1854-1856, May 2004.

[75] Y. S. Hwang and J. Peters, private communication, 2004

[76] T. Kuo and J. Peters, private communication, 1999.

[77] H. Oguri, Y. Okumura, K. Hasegawa, Y. Namekawa, and T. Shimooka, "Development of an $\mathrm{H}^{-}$ion source for the high intensity proton linac," Rev. Sci. Instrum., vol. 73, no. 2, pp. 1021-1023, Feb. 2002.

[78] H. Oguri, private communication, 2005.

[79] Brookhaven Nat. Lab. 50727, K. Prelec, Ed., Upton, NY, 1977, pp. 79-96.

[80] V. G. Dudnikov, "20 years of cesium catalysis for negative ion production in gas discharges," Rev. Sci. Instrum., vol. 63, no. 4, pp. 2660-2668, Apr. 1992.

[81] V. Dudnikov, "Thirty years of surface plasma sources for efficient negative ion production," Rev. Sci. Instrum., vol. 73, no. 2, pp. 992-994, Feb. 2002

[82] M. L. Yu, "Work-function dependence of negative-ion production during sputtering," Phys. Rev. Lett., vol. 40, no. 9, pp. 574-577, Feb. 1978.

[83] P. Allison, H. V. Smith, Jr., and J. D. Sherman, "H- ion source research at Los Alamos," in Brookhaven Nat. Lab. 51 304, T. Sluyters, Ed., Upton, NY, 1980, pp. 171-177.

[84] M. Bacal, J. Bruneteau, and P. Devynck, "Method for extracting volume produced negative ions," Rev. Sci. Instrum., vol. 59, no. 10, pp. 2152-2157, Oct. 1988.

[85] Yu. I. Belchenko, G. I. Dimov, and V. G. Dudnikov, "Emission of intense negative-ion fluxes from a surface bombarded by fast particles from a discharge," Izvestiya Akademii Nauk SSSR. (PAC'87), vol. 37, no. 12, pp. 2573-2577, 1973 .

[86] C. W. Schmidt and C. D. Curtis, "An H- ion source for accelerator use," in Brookhaven Nat. Lab. 50 727, K. Prelec, Ed. Upton, NY, 1977, pp. 123-123.

[87] J. G. Alessi, J. M. Brennan, A. Kponou, and K. Prelec, "H- source and beam transport experiments for a new RFQ," in Proc. Particle Accel. Conf., 1987, pp. 304-306.

[88] J. G. Alessi, "Performance of the magnetron $\mathrm{H}^{-}$source on the BNL 200 MeV LINAC," . ser. AIP Conf. Proc., W. Chou, Y. Mori, D. Neuffer, and J.-F. Osteguy, Eds. New York: Amer. Inst. Phys., 2002, vol. 642, pp. 279-281.

[89] R. Sidlow, P. J. S. Barratt, A. P. Letchford, M. Perkins, and C. W. Planner, "Operational experience of penning $\mathrm{H}^{-}$ion sources at ISIS," in Proc. Eur. Particle Accel. Conf., Barcelona, Spain, Jun. 10-13, 1996, pp. $1806-1808$
[90] J. W. G. Thomason and R. Sidlow, "ISIS ion source operational experience," in Proc. Eur. Particle Accel. Conf., Vienna, Austria, Jun. 26-30, 2000, pp. 1625-1627.

[91] A. S. Belov, O. T. Frolov, V. S. Klenov, and V. P. Yakushev, "Ion sources for linac of Moscow institute of nuclear research," Rev. Sci. Instrum., vol. 63, no. 4, pp. 2622-2624, Apr. 1992.

[92] D. C. Faircloth, J. W. G. Thomason, R. Sidlow, and M. O. Whitehead, "Advances in the ion source research and development program at ISIS," . ser. AIP Conf. Proc., J. D. Sherman and Yu. I. Belchenko, Eds. New York: Amer. Inst. Phys., 2004, vol. 763, pp. 243-253.

[93] A. M. Anikeichik, A. S. Belov, A. V. Vasuchenko, S. K. Esin, O. V. Elsukov, V. S. Klenov, V. V. Kish, V. E. Kuzik, S. A. Kubalov, O. S. Korolev, O. T. Frolov, and V. P. Yakushev, "Injectors for high-intensity linear accelerator of INR Moscow meson factory," in Proc. Linear Accel. Conf., Williamsburg, VA, Oct. 3-7, 1988, CEBAF-Report-89-001, pp. 660-662.

[94] O. R. Sander, G. P. Boicourt, and W. B. Cottingame, "Transverse emittance of a $2.0 \mathrm{MeV}$ RFQ beam with high brightness," IEEE Trans. Nucl. Sci., vol. NS-32, no. 5, pp. 2588-2590, May 1985.

[95] K. F. Johnson, O. R. Sander, W. H. Atkins, G. O. Bolme, S. Brown, R. Connolly, R. Garnett, J. D. Gilpatrick, F. W. Guy, W. B. Ingalls, C. Little, R. A. Lohsen, G. Neuschaefer, J. Power, K. Saadatmand, D. P. Sandoval, R. R. Stevens, Jr., G. Vaughn, E. A. Wadlinger, R. Weiss, and V. Yuan, "Commissioning of the ground test accelerator RFQ," in Proc. 1992 Linear Accel. Conf., Ottawa, ON, Canada, AECL-10 728, pp. 64-66.

[96] P. W. Allison, "A direct extraction $\mathrm{H}^{-}$ion source," IEEE Trans. Nucl. Sci., vol. NS-24, no. 3, pp. 1594-1596, Jun. 1977.

[97] - "Experiments with a Dudnikov-type $\mathrm{H}^{-}$ion source," in Brookhaven Nat. Lab. 50727, K. Prelec, Ed. Upton, NY, 1977, pp. $119-122$.

[98] J. D. Sherman, P. Allison, and H. V. Smith, Jr. " $\mathrm{H}^{-}$beam formation from a penning surface plasma source using circular emission-extractor electrodes," in Brookhaven Nat. Lab. 51 304, T. Sluyters, Ed. Upton, NY, 1980, pp. 184-188.

[99] H. V. Smith, Jr., J. D. Sherman, and P. Allison, "Pulsed H- beams from penning SPS sources equipped with circular emitters," in Proc. Linear Accel. Conf., Williamsburg, VA, Oct. 3-7, 1988, CEBAF-Report-89-001, pp. 164-166.

[100] D. C. Faircloth and J. W. G. Thomason, "Thermal modeling of the ISIS $\mathrm{H}^{-}$ion source," Rev. Sci. Instrum., vol. 75, no. 5, pp. 1738-1740, May 2000.

[101] H. V. Smith, Jr., N. M. Schnurr, D. H. Whitaker, and K. E. Kalash, "Hion source with high duty factor," in Proc. Particle Accel. Conf., 1987, pp. 301-303.

[102] H. V. Smith, Jr., P. Allison, and J. D. Sherman, " $\mathrm{H}^{-}$and $D^{-}$scaling laws for penning surface plasma sources," Rev. Sci. Instrum., vol. 65, no. 1, pp. 123-128, Jan. 1994

[103] Proc. 7th European Spallation Source General Meeting, Seggau, Austria, Sep. 26-29, 2001

[104] J. D. Sherman, W. B. Ingalls, G. Rouleau, H. V. Smith, Jr., J. Thomason, R. Sidlow, R. Ferdinand, and R. Gobin, "Review of scaled penning $\mathrm{H}^{-}$ surface plasma source with slit emitters for high duty factor linacs," in Proc. Eur. Particle Accel. Conf., La Villette, France, Jun. 3-7, 2002, pp. 284-286.

[105] Yu. Belchenko and V. Savkin, "Direct current $\mathrm{H}^{-}$source for the medicine accelerator," Rev. Sci. Instrum., vol. 75, no. 5, pp. 1704-1704, May 2004.

[106] Yu. Belchenko, I. Ivanov, and I. Piunov, "Study of direct current negative ion source for medicine accelerator," . ser. AIP Conf. Proc., J. D. Sherman and Yu. I. Belchenko, Eds. New York: Amer. Inst. Phys. 2004, vol. 763, pp. 325-331.

[107] Yu. I. Belchenko and A. S. Kupriyanov, "Negative hydrogen ion production in the hollow cathode penning surface-plasma source," Rev. Sci. Instrum., vol. 65, no. 2, pp. 417-425, Feb. 1994.

[108] — "Surface-plasma sources with an intense cathode and anode productions of negative ions," Rev. Sci. Instrum., vol. 65, no. 4, pp. 1179-1181, Apr. 1994.

[109] Y. Mori, A. Takagi, K. Ikegami, and S. Fukumoto, "The cusp H- source at KEK," . ser. AIP Conf. Proc., J. Alessi, Ed. New York: Amer. Inst. Phys., 1986, vol. 158, pp. 378-383.

[110] K. N. Leung and K. W. Ehlers, "Self-extraction negative ion source," Rev. Sci. Instrum., vol. 53, no. 6, pp. 803-809, Jun. 1982.

[111] K. W. Ehlers, "Negative ion sources for neutral beam systems," in Proc. Inter. Ion Eng. Congress, ISIAT '83 and IPAT '83, Kyoto, Japan, 1983, pp. 59-69. 
[112] E. H. A. Granneman, J. J. C. Geerlings, J. N. M. van Wunnik, P. J. van Bommel, H. J. Hopman, and J. Los, " $\mathrm{H}^{-}$and $\mathrm{Li}^{-}$formation by scattering $\mathrm{H}^{+}, \mathrm{H}^{2+}$, and $\mathrm{Li}^{+}$from cesiated tungsten surfaces," . ser. AIP Conf. Proc., K. Prelec, Ed. New York: Amer. Inst. Phys., 1983, vol. 111 , pp. 206-219.

[113] G. Rouleau, E. Chacon-Golcher, E. Geros, E. G. Jacobson, B. J. Meyer, B. A. Prichard, Jr., J. Sherman, J. E. Stelzer, and R. R. Stevens, Jr., "Hsurface converter source development at Los Alamos," in Proc. Particle Accel. Conf., vol. 1, May 12-16, 2003, pp. 73-75.

[114] B. A. Prichard, Jr. and R. R. Stevens, Jr., "Status of the SPSS H- ion source development program," Los Alamos Nat. Lab., Los Alamos, NM, Tech. Rep. LA-UR-02-547, 2002.

[115] J. Sherman, A. Arvin, E. Chacon-Golcher, E. Geros, E. Jacobson, B. Meyer, P. Naffziger, G. Rouleau, S. Schaller, J. Stelzer, and T. Zaugg, "Development of a 0.025-A, 12\% df H- source for LANSCE," in Proc. European Particle Accel. Conf., Lucerne, Switzerland, Jul. 5-9, 2004, pp. $1500-1502$.

[116] A. Takagi, Y. Mori, K. Ikegami, and S. Fukumoto, "KEK multicusp negative hydrogen ion source," IEEE Trans. Nucl. Sci., vol. NS-32, no. 5, pp. 1782-1784, May 1985

[117] I. S. K. Gardner. Status of the european spallation source design study. presented at Proc. Accel. Conf.. [Online]

[118] F. Gerigk and M. Vretenar, "Design of a $120 \mathrm{MeV} \mathrm{H}^{-}$LINAC for CERN high-intensity applications," in Proc. Linear Accel. Conf., Gyeongju, Korea, Aug. 19-23, 2002, pp. 73-73.

[119] F. Naito, "The jaeri/kek joint project and its performance," in Proc. 2002 Linear Accelerator Conf., Gyeongju, Korea, Aug. 19-23, 2002, pp. 566-566.

[120] Proton Driver Project. Fermilab, Batavia, IL. [Online]. Available: http://protondriver.fnal.gov/

[121] G. W. Foster, W. Chou, and E. Malamud, Eds., An 8 GeV Superconducting Injector Linac Design Study. Batavia, IL: Fermilab, 2005.

[122] R. R. Stevens and D. H. Fitzgerald, "High Brightness H- Source for LANSCE," Los Alamos Nat. Lab., Los Alamos, NM, Tech. Ref. Document $1.1,1997$.

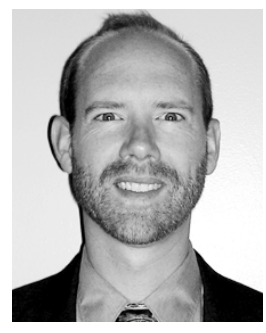

Douglas P. Moehs was born in Petersburg, VA, in September 1967. He received the B.S. degree in physics from Michigan Technological University, Houghton, Michigan, in 1989 and the Ph.D. degree in atomic and molecular physics from Texas A\&M University, College Station, in 1998. His Ph.D. dissertation was entitled Metastable Level Lifetime measurements on confined highly charged metal ions, UMI Disseration Services (1998).

From 1998 to 2001, he was with the Physics Division, Argonne National Laboratory, Argonne, IL, working on electron cyclotron resonance ion source development and emittance diagnostic tools under a postdoctoral appointment. In 2001, he became an Associate Scientist at Fermi National Accelerator Laboratory, Batavia, IL, where he presently works on negative hydrogen ion source development, low energy beam transport, and fast beam chopping of space charge dominated beams. His other publications not cited in the reference section include: Completion of the ATLAS ECR-I ion source upgrade project, D. P. Moehs, et al. Rev. Sci. Instrum., vol. 73, pp. 576 (2002) and Measured Lifetimes of Levels of Metastable Excited Configurations of Cl-Like Mn IX and Fe X, Phys. Rev. Lett., vol. 85, pp. 38 (2000).

Dr. Moehs has been a member of the American Physical Society since 1998. Recently, he has been actively involved in Fermilab's Summer Internship in Science and Technology program. In 2004, he received a laboratory merit award for his work as Fermilab Run Coordinator.

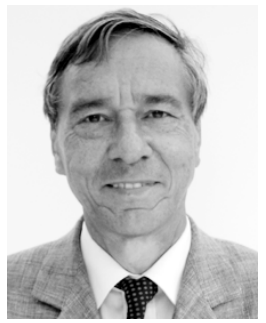

Jens Peters received the diploma in electrical engineering from the Technische Universitat, München, Germany, in 1975, and the Ph.D. degree in physics from the University of Frankfurt, Frankfurt, Germany, in 2001.

He joined Deutsches Elektronen-Synchrotron (DESY), Hamburg, Germany, in 1975 after receiving the diploma and performing development work at the Fujitsu Central Laboratory, Gifu, Japan. He performed work on the design of RF systems and research and development work for PETRA in Germany until 1979, when he left DESY for a sabbatical year at Cornell University, Ithaca, NY. After he returned from the U.S., he participated in the construction of the DESY HERA H- LINAC III. When the LINAC III became operational, he improved the magnetron source and built the new HERA RF $\mathrm{H}^{-}$source. He received the Ph.D. degree about the development of this RF source. $\mathrm{He}$ continues research in $\mathrm{H}^{-}$production, $\mathrm{RF}$, and linear accelerators.

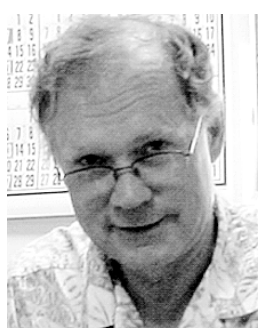

Joseph Sherman was born in Portland, OR, in April, 1945. He received the B.S. degree in chemistry from Oregon State University, Corvallis, in 1967, and the $\mathrm{Ph} . \mathrm{D}$. degree from the University of California, Berkeley, in 1973, using the 88-in cyclotron in studies of low-energy nuclear reactions.

He then took a postdoctoral appointment at the Physics Division, Los Alamos National Laboratory (LANL), Los Alamos, NM, to continue studies of high resolution nuclear reactions using a Q3D magnetic spectrometer. From 1975 to 1977, he was a Research Associate at Carnegie-Mellon University, Pittsburgh,, PA, assigned to their Medium-energy Nuclear Physics Group at the LANL Meson Physics Facility. During this time, he developed and used large helical position sensitive detectors for the study of low and medium energy nuclear reactions. In January, 1978, he started studies of $\mathrm{H}^{-}$sources for accelerators with the newly formed Accelerator Technology Division, LANL. For the next 12 years, he participated in the production and transport of very bright $\mathrm{H}^{-}$beams based on the cesiated Penning $\mathrm{H}^{-}$surface plasma source. This team was led by P. Allison, and was based on the Budker Institute of Nuclear Physics discovery of the role of cesium catalysis in $\mathrm{H}^{-}$sources. In addition to the fundamental $\mathrm{H}^{-}$source studies, three $\mathrm{H}^{-}$injectors were built for the then new RFQ accelerators being built at LANL. In 1990, he took leave from LANL for one year to study dc proton sources at the Paul Scherrer Institute, Switzerland. This work evolved into collaboration with Chalk River Laboratories, which led to the development of a $130-\mathrm{mA}, 75-\mathrm{keV}$ dc mode proton injector based on microwave technology. This injector was used in the successful commissioning of a $100-\mathrm{mA}, 6.7-\mathrm{MeV} \mathrm{CW}$ mode RFQ. This work occurred from 1992 to 2000. In 2001, he took another one year leave from LANL to work at Commissariat a l'Energie Atomique (CEA), Saclay, France, on the application of microwave-plasma interaction in the formation of $\mathrm{H}^{-}$beams. The first low-current $\mathrm{H}^{-}$beams were extracted from the Saclay microwave source during this year. In addition, paper studies involving LANL, CEA-Saclay, and Rutherford-Appleton Laboratories of scaled versions of the cesiated Penning $\mathrm{H}^{-}$source were made for the European Spallation Source project. It was predicted a $100 \mathrm{~mA}, 5 \%$ duty factor beam with appropriate emittance could be produced from the Penning source. From 2002 to 2005, he worked on increasing the $\mathrm{H}^{-}$current from the Los Alamos Neutron Science Center (LANSCE) surface converter source. Sherman retired from the LANL in June, 2005. 